\title{
Aplicaciones de la biogeografía histórica a la distribución de las plantas mexicanas
}

\author{
Historical biogeography applied to the distribution of Mexican plants
}

\author{
Isolda Luna-Vega \\ Departamento de Biología Evolutiva, Facultad de Ciencias, Universidad Nacional Autónoma de México. Apartado postal 70-399, 04510 Ciudad \\ Universitaria, México, D.F. \\ Correspondencia:ilv@hp.fciencias.unam.mx
}

\begin{abstract}
Resumen. Los patrones biogeográficos de la flora mexicana, tanto en número de especies como de endemismos y relaciones entre áreas, han sido explicados a la luz de 3 teorías: 1) la dispersalista, donde México se considera receptor de elementos de diferentes fuentes o áreas geográficas, sobre todo si se toma en cuenta que está ubicado en la zona de transición entre la regiones neártica y neotropical que, junto con los autóctonos, han constituido un complejo mosaico de especies con diferentes orígenes, tanto espaciales como temporales; 2) la teoría de la vicarianza, que propone que hay una estrecha correspondencia entre la historia de la Tierra y la historia de la biota, por lo que el número de especies y su distribución tendrían que explicarse esencialmente de acuerdo con la compleja historia geológica de México y 3) el efecto de las glaciaciones pleistocénicas, que mediante eventos ecológicos e históricos explica los patrones contemporáneos de la distribución, con base en los cambios paleoclimáticos del pasado reciente. El debate fundamental al interior de la biogeografía histórica ha recaído en la importancia que tiene como fuente de evidencia para la taxonomía y viceversa. La biogeografía histórica, aunque posee una estrecha relación con la sistemática, es una disciplina independiente dentro de la biología comparada, que puede operar paralelamente a esta última. La biogeografía está en un proceso de revolución conceptual que ha propiciado la revisión de sus fundamentos y métodos. La utilización de diferentes métodos de una manera integrativa en un mismo análisis permite maximizar las bondades de cada uno de ellos.
\end{abstract}

Palabras clave: patrones biogeográficos, dispersión, vicarianza, refugios pleistocénicos, fitogeografía, México.

\begin{abstract}
Biogeographical patterns of the Mexican flora are explained based on 3 different theories, considering number of species, endemisms, and relations among areas: 1) dispersalist theory, where Mexico has been considered as the receiver of elements of different sources or geographic areas, considering that it is located in the transition zone between the Nearctic and Neotropical regions, which along the autochthonous ones form a complex mixture of species with different origins, both spatial and temporal, 2) vicariant theory, that proposes a close relationship between the earth's history and the history of the biota, so that the number of species and their distribution may be explained by the complex geologic history of Mexico, and 3) pleistocenic glaciations, which explain the recent distributional patterns of plants based on ecological and historical arguments, based on paleoclimatic changes of the recent past. A continuous debate within historical biogeography has high lighted the importance of biogeography as source of evidence for taxonomy and vice versa. Historical biogeography has a close relationship with systematics, but is an independent discipline within comparative biology. Biogeography is undergoing a conceptual revolution that is causing a revision of its fundamentals and methods. The utilization of different methods in an integrative manner in the same analysis may maximize the advantages of each one.
\end{abstract}

Key words: biogeographic patterns, dispersal, vicariance, pleistocene refuges, phytogeography, Mexico.

\section{Introducción}

Para la comunidad científica y para la sociedad en general existe un compromiso común en la conservación de la biodiversidad mundial y frecuentemente se vuelve la vista hacia casos como el de México que, a la vez que

Recibido: 12 enero 2007; aceptado: 21 enero 2008 se considera un centro de alta biodiversidad (Rzedowski, 2005), parte de su territorio ha sido identificado como hotspot, es decir, un centro de gran riqueza y alta fragilidad ecológica, donde existen concentraciones excepcionales de especies endémicas (Mittermeier y Mittermeier, 1992; Flores-Villela y Gerez, 1999; Myers et al., 2000). Actualmente se considera que en el mundo existen 25 hotspots, que comprenden aproximadamente el $1.4 \%$ de la 
superficie de la Tierra, donde está confinado el 44\% de las especies de plantas vasculares y el $35 \%$ de los vertebrados (Myers et al., 2000).

La crisis de la biodiversidad ha conducido a los especialistas a discutir desde la definición del concepto (MacArthur, 1965 y 1972; Platnick, 1992), su medición y evaluación (Pielou, 1975; Magurran, 1989), su explicación causal, que involucra la búsqueda de los orígenes y mecanismos de por qué hay áreas con mayor biodiversidad que otras de tamaño semejante, hasta la naturaleza de la crisis de la biodiversidad y las posibles estrategias generales para entenderla (Wilson, 1989; Dirzo, 1990; Halffter, 1992; Soulé, 1992) y mantenerla (Eldredge, 1998; Novacek, 2001; Levin y Levin, 2002; Laurance, 2006).

En mayo del 2004 se celebró en la ciudad de México una reunión organizada por la Comisión Nacional para el Conocimiento y Uso de la Biodiversidad (CONABIO) y el grupo Diversitas-México que tuvo como fin convocar a una parte importante de los interesados en cuestiones de diversidad de México y cuyos resultados fueron sintetizados por Halffter et al. (2005).

México está considerado uno de los 12 países con megadiversidad junto con Colombia, Brasil, China, Australia e Indonesia, por mencionar algunos. En su territorio alberga alrededor del $10 \%$ de las especies del planeta; ocupa el segundo lugar en el mundo en riqueza de reptiles (Uetz, 2000) y mamíferos y el cuarto en anfibios y plantas (Mittermeier y Mittermeier, 1992; Toledo y Ordoñez, 1993). Esta diversidad biológica no sólo se refiere al número total de especies reconocidas (Rzedowski, 1978; Toledo, 1988; Villaseñor, 2003, 2004), sino también al alto número de variantes fisonómicas de su vegetación (Rzedowski, 1992; González-Medrano, 2003) y a su gran número de provincias bióticas, definidas con base en la distribución de diferentes grupos taxonómicos endémicos a éstas (Arriaga et al., 1997; Morrone, 2005).

Existen varias propuestas de regionalización del territorio mexicano por varios autores (v. gr. Smith, 1941; Goldman y Moore, 1946; Stuart, 1964; Álvarez y Lachica, 1974; Rzedowski, 1978; Kohlmann y Sánchez, 1984; Casas-Andreu y Reyna-Trujillo, 1990; FerrusquíaVillafranca, 1990; Ramírez-Pulido y Castro-Campillo, 1990; Rzedowski y Reyna-Trujillo, 1990; Morrone 2001, 2005), que por lo general concluyen en reconocer entre 14 y 21 provincias que pueden considerarse áreas con un alto número de especies endémicas. Recientemente se ha propuesto subdividir alguna de estas provincias en distritos bióticos con base en subespecies endémicas y formaciones fisiográficas menores.

Las explicaciones históricas acerca de la gran biodiversidad de México son variadas. Se pueden reconocer entre ellas 3 ideas principales, a veces defendidas o simplemente adoptadas, indistintamente, por un mismo autor. Para algunos de ellos (v. gr. Halffter, 1964a; Rzedowski, 1978), México tiene una gran diversidad debido a que en su territorio se entrelazan 2 de las principales regiones biogeográficas del planeta, la neártica y la neotropical. La mezcla de la flora y la fauna de ambas, con los elementos autóctonos produjo un gran número de especies. Con esta primera hipótesis se han gestado la mayoría de los trabajos biogeográficos de México, principalmente hasta finales del siglo $\mathrm{XX}$, y se le conoce como corriente dispersalista o dispersionista (ContrerasMedina et al., 2001).

La segunda teoría, la de la vicarianza, sostiene que tanto la diversidad biológica como el endemismo sólo pueden explicarse por una estrecha correspondencia entre la historia de la Tierra y la historia de la biota. El trabajo pionero para México es el de Rosen (1978), quien siguiendo este enfoque analizó áreas mexicanas con base en peces de agua dulce; después de esta fecha, se han producido más de una veintena de trabajos con diferentes metodologías en biogeografía vicariante (panbiogeografía, biogeografía de la vicarianza, análisis de parsimonia de endemismos) analizando áreas mexicanas. Según este punto de vista, México tiene una gran cantidad de especies y endemismos debido a su compleja historia tectónica desde finales del Mesozoico. Las diferencias fundamentales entre dispersión y vicarianza pueden revisarse en la figura 1.

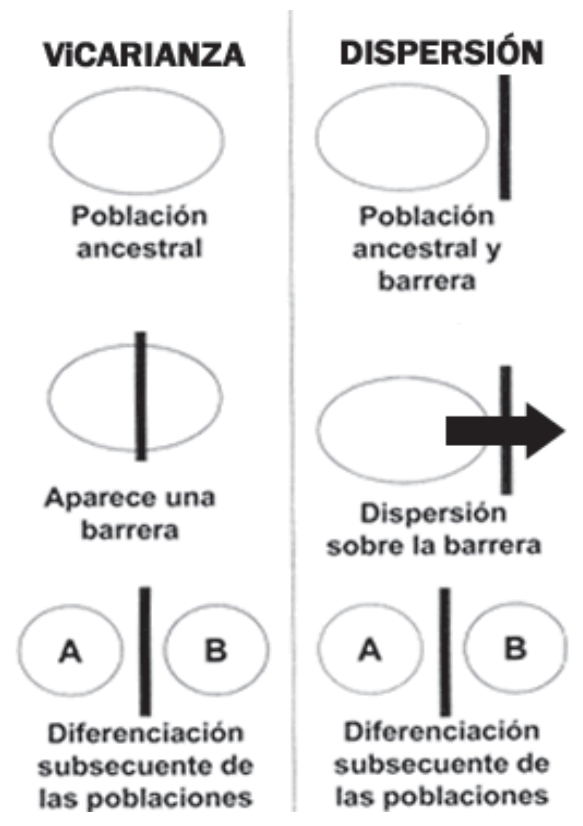

Figura 1. Diferencias entre 2 procesos distintos dentro de la biogeografía histórica, vicarianza y dispersión, para explicar la distribución disyunta de 2 taxones. Modificado de Crisci et al. (2000). 
Un tercer enfoque, que utiliza tanto explicaciones de tipo histórico como ecológico (Myers y Giller, 1988), sostiene que las glaciaciones del Pleistoceno han tenido un efecto determinante en la distribución de plantas y animales (Haffer, 1969). Esta hipótesis se basa en que México se encuentra ubicado en una zona que ha estado sujeta a cambios paleoclimáticos y algunos tectónicos en el pasado reciente (Toledo, 1982; Escalante y Llorente, 1985; Flores-Villela, 1991; Flores-Villela y Gerez, 1999) y que cada sucesión de eventos de avance y retroceso de glaciares provocó la contracción, aislamiento, diferenciaciónespeciación y después la expansión de las áreas de distribución de las nuevas especies, con el consecuente incremento de la riqueza. Otro trabajo representativo de esta corriente es el de Lozano-García y Vázquez-Selem (2005); sin embargo, muchos de los trabajos que han utilizado este proceso para explicar la distribución actual de los organismos han sido de otra índole, sin que su interés principal sea el biogeográfico.

La polémica mundial en torno a estas ideas ha sido agitada y renovadora (Llorente y Espinosa, 1991) y abarca varios terrenos de conocimiento en disputa alrededor de la biología comparada. Cada hipótesis involucra tanto la base teórica para la percepción y concepción de las regiones biogeográficas como el establecimiento de criterios de evaluación de áreas de conservación de la biodiversidad, y además genera elementos para la formulación de estrategias de protección y uso de los recursos biológicos (Vane-Wright et al., 1991).

En este trabajo se exponen los enfoques mencionados arriba y se postulan las predicciones que se derivan de cada uno de ellos. Se hace una evaluación de estos 3 enfoques $\mathrm{y}$ se establecen los posibles lineamientos que pudiesen conducir las investigaciones futuras sobre la distribución geográfica de las plantas mexicanas, desde una nueva perspectiva teórica y metodológica más integradora.

\section{La geografía de las plantas}

Hablar de "fitogeografía" restringiría mucho la variedad de enfoques con los que se ha abordado el estudio de la geografía de las plantas. El concepto de fitogeografía ha sido utilizado por diferentes autores, a veces en un contexto más bien ecológico y otras veces histórico. Este término tuvo sus orígenes en los trabajos de Stromeyer (1800) y Schouw (1823). Stromeyer introdujo el término phytogeographia como una rama de la ciencia denominada "geografía de las plantas". En el Cuadro 1 se ofrece una traducción de los términos empleados por varios autores para designar las 3 ramas principales de esta ciencia. Wulff (1950) la nominó como “geografía histórica de plantas", ciencia que estudia la distribución vegetal con base en sus áreas presentes y pasadas, lo que en conjunto con la elucidación del origen e historia del desarrollo de las floras genera la clave para entender la historia de la biota. Desgraciadamente, el extenso trabajo de Wulff, publicado en ruso en 1932, fue traducido al inglés y dado a conocer hasta 1950, lo que retrasó su difusión y lectura.

Hay 2 patrones que fueron reconocidos y estudiados por los botánicos a lo largo de los últimos 3 siglos, a pesar de que los cuestionamientos sobre la distribución de los seres vivos son casi tan antiguos como la humanidad: las zonas de vida y las regiones. Los patrones zonales de la vegetación involucran la observación de tendencias de cambio desde grupos de formas de vida o fisonomía hacia otros distintos; estas tendencias implican también regularidad. El reemplazamiento de fisonomías de vegetación desde el ecuador hacia los polos se presenta de forma similar en cualquier continente con pocas variaciones. Hay tendencias latitudinales, altitudinales y de fachadas u orientaciones (por efecto de sombra lluviosa); también hay efectos de la pendiente, los constituyentes de la roca madre y otros agentes físicos o ecológicos. Las regiones biogeográficas, en cambio, se reconocen por la discontinuidad y correspondencia en la distribución de los seres vivos, lo que conocemos por alopatría y homopatría. Una región está definida por la distribución concurrente de varias especies o taxones superiores, que son a su vez alopátridas respecto a otras especies o taxones superiores que conformen otra región. No hay 2 regiones iguales por discontinuidad, individualidad y congruencia entre distribuciones.

Actualmente, como lo sustentan Crisci et al. (2000), se reconoce que la biogeografía histórica ha estado influenciada por 3 fuerzas externas: la tectónica de placas de Wegener (1929), como paradigma dominante en las geociencias; la influencia de la sistemática filogenética de Hennig (1950, 1968), como lenguaje básico de la biología comparada, y una diferente percepción que hoy tienen los biólogos de la biogeografía, donde no se admite a priori un factor o evento particular como causal de las áreas de distribución de los organismos. Esto ha provocado que la biogeografía histórica esté en un proceso de revolución conceptual y metodológica que ha propiciado una revisión de sus fundamentos y conceptos.

A continuación se resumen las contribuciones que han tenido un impacto trascendental en la biogeografía de las plantas a través del tiempo (Cuadro 2).

\section{Desarrollo de la biogeografía histórica en México}

El desarrollo de esta disciplina en el país es relativamente reciente. Se origina en las últimas décadas en la Universidad Nacional Autónoma de México (UNAM) y el Instituto Politécnico Nacional (IPN). Han 
Cuadro 1. Utilización del término fitogeografía y términos relacionados. Traducción al español del cuadro de Wulff (1950)

\begin{tabular}{|c|c|c|c|}
\hline \multirow[t]{2}{*}{ Autor } & \multicolumn{3}{|c|}{ Ramas de la geografía de las plantas } \\
\hline & Florístico & Ecológico & Histórico \\
\hline Willdenow (1792) & Historia de las plantas & Historia de las plantas & Historia de las plantas \\
\hline Stromeyer (1800) & Geografía vegetal & Fito-geografía & Historia geográfica vegetal \\
\hline Humboldt (1807) & Geografía de plantas & Geografía de plantas & Geografía de plantas \\
\hline De Candolle, Aug. (1820) & Geografía botánica & Geografía botánica & Geografía botánica \\
\hline Schouw (1822) & Geografía de plantas & Geografía de plantas & Historia de las plantas \\
\hline $\begin{array}{l}\text { De Candolle, Alphonse } \\
\text { (1855) }\end{array}$ & --- & --- & $\begin{array}{l}\text { Geografía botánica "razonada" } \\
\text { (epiontología) }\end{array}$ \\
\hline Grisebach (1866) & Topografía geobotánica & Climatología geobotánica & Geología geobotánica \\
\hline Drude (1890) & $\begin{array}{l}\text { Topografía geobotánica. } \\
\text { Fisionomía vegetal }\end{array}$ & Climatología geobotánica & Geología geobotánica \\
\hline Engler (1899) & $\begin{array}{l}\text { Geografía de plantas } \\
\text { florística }\end{array}$ & $\begin{array}{l}\text { Geografía de plantas } \\
\text { fisiológica }\end{array}$ & $\begin{array}{l}\text { Desarrollo de la historia de la } \\
\text { geografía de plantas }\end{array}$ \\
\hline Diels (1908) & $\begin{array}{l}\text { Geografía de plantas } \\
\text { florística }\end{array}$ & $\begin{array}{l}\text { Geografía de plantas } \\
\text { ecológica }\end{array}$ & Geografía de plantas genética \\
\hline Graebner (1910) & $\begin{array}{l}\text { Geografía de plantas } \\
\text { florística }\end{array}$ & $\begin{array}{l}\text { Geografía de plantas } \\
\text { ecológica }\end{array}$ & Geografía de plantas genética \\
\hline Rübel (1922) & Geobotánica corológica & Geobotánica ecológica & Geobotánica genética \\
\hline Schröter (1913) & --- & --- & $\begin{array}{l}\text { Geografía de plantas genética o } \\
\text { epiontología }\end{array}$ \\
\hline Hayek (1926) & $\begin{array}{l}\text { Geografía de plantas } \\
\text { florística }\end{array}$ & $\begin{array}{l}\text { Geografía de plantas } \\
\text { ecológica }\end{array}$ & $\begin{array}{l}\text { Desarrollo de la historia o } \\
\text { geografía de plantas histórica }\end{array}$ \\
\hline
\end{tabular}

sido pioneros Jerzy Rzedowski, en el campo de la botánica, y Carlos Hoffmann, Alfredo Barrera y Gonzalo Halffter en el de zoología. Según Llorente y Espinosa (1991), los primeros trabajos de esta índole no ofrecen en general cuestionamientos teóricos y metodológicos equivalentes a los que se proponen en las escuelas modernas de biogeografía histórica. Actualmente entre las instituciones que realizan algún tipo de estudio en biogeografía histórica están el Instituto de Ecología, A.C. (principalmente Guzmán, Halffter, Morón y Rzedowski; véase Cuadros 3 y 4), Instituto de Biología, UNAM (Delgado, Delgadillo, Johannsen, Magallón, Martínez-Meyer, Sánchez-Cordero y Villaseñor; véase Cuadro 3), Facultad de Ciencias, UNAM (Escalante, Flores, Llorente, Luna, Morrone, Navarro, entre otros; véase Cuadro 3), ENEP-Zaragoza (Bueno y Espinosa) y ENEP-Iztacala (Dávila, Lira y Téllez), Instituto de Ecología, UNAM (Eguiarte y Piñero), Centro de Investigaciones en Ecosistemas (Oyama),
Instituto de Geología, UNAM (Lozano y Cevallos-Ferriz), Universidad Autónoma del Estado de Hidalgo (Márquez, i.e. Morrone y Márquez, 2001) y Centro de Educación Ambiental e Investigación Sierra de Huautla (Corona et al., 2007; Toledo et al., 2007).

En el Cuadro 3 pueden revisarse algunos de los trabajos más importantes que se gestaron desde el siglo XIX sobre fitogeografía de México, exceptuando los de Jerzy Rzedowski, los cuales se sintetizan en el Cuadro 4. Los trabajos más recientes (a partir de 1990) se discuten aparte. Debe resaltarse que fueron Humboldt y Bonpland (1805) los autores que mencionan por primera vez algunas afinidades florísticas de México. De manera general, estos primeros trabajos han tenido como objetivo: 1) intentar explicar el origen de algunos elementos de la flora mexicana, esto es, si los elementos que la componen han provenido del norte, sur, alguna otra área o han evolucionado in situ; 2) reconocer los elementos endémicos 
Cuadro 2. Principales autores que han contribuido al desarrollo de la biogeografía histórica de las plantas

\begin{tabular}{|c|c|}
\hline Autor & Contribuciones más importantes \\
\hline Joseph de Acosta (1570) & $\begin{array}{l}\text { - Encuentra que muchas especies de América son distintas a las del Viejo } \\
\text { Mundo, aunque tengan el mismo nombre. } \\
\text { - Realiza los primeros análisis acerca del origen de la flora. }\end{array}$ \\
\hline Carl Linneo (1744) & $\begin{array}{l}\text { - Adopta la idea bíblica de que todas las especies proceden de un centro } \\
\text { único de origen el Edén o Paraíso, donde había una montaña con todas } \\
\text { las condiciones climáticas, y llegaron a donde actualmente viven por } \\
\text { dispersión. }\end{array}$ \\
\hline Alexander von Humboldt (1816) & $\begin{array}{l}\text { Descubre que las observaciones de Georges Louis Leclerc, conde de } \\
\text { Buffon (1761) se aplican también a las plantas, por lo que postula este } \\
\text { hecho como una ley (Ley de Buffon). } \\
\text { - Describe los patrones de distribución zonal de las formas de vida vegetal. }\end{array}$ \\
\hline Augustin de Candolle (1820) & $\begin{array}{l}\text { - Descubre que la mayoría de las plantas tienen distribución localizada y } \\
\text { las llama endémicas o aborígenes. } \\
\text { - Descubre que es frecuente que } 2 \text { o más especies endémicas diferentes } \\
\text { tengan distribuciones coincidentes y conformen regiones. } \\
\text { - Establece que la naturaleza de las regiones es histórica. } \\
\text { - Divide al mundo en } 20 \text { regiones botánicas, siendo México una de ellas. } \\
\text { - Da las bases para la separación de las } 2 \text { grandes ramas de la biogeografía: } \\
\text { histórica y ecológica (estudio de las habitaciones y estaciones) }\end{array}$ \\
\hline Joseph D. Hooker (1844-1847) & $\begin{array}{l}\text { Encuentra que la distribución actual de las floras australes se explica } \\
\text { mejor por la existencia de una sola área de distribución anteriormente } \\
\text { continua que se fragmentó por eventos geológicos. }\end{array}$ \\
\hline
\end{tabular}

Charles Darwin (1859)

Willi Hennig (1950)

en inglés: 1966

en español: 1968

- Sugiere que las especies no se originan donde viven, sino que proceden de unos pocos centros de origen.

- Reconoce que es posible descubrir los vínculos evolutivos entre las regiones.

- Sienta las bases para el surgimiento de la biogeografìa filogenética, ya que:

1) Propone un método para construir clasificaciones filogenéticas a partir de relaciones genealógicas.

2) Aplica la regla de desviación corológica para ubicar los centros de origen de los grupos.

Reconoce a la vicarianza como elemento fundamental en las explicaciones biogeográficas.

Léon Croizat (1958)

- Postula la idea de que la biota y la Tierra evolucionan juntas.

- Sugiere que no existe una biogeografía de plantas y otra de animales, sino que la historia de la Tierra afecta del mismo modo a todos los organismos. Los organismos han adquirido su distribución actual por vicarianza. Formula un método basado en trazos, al que llama panbiogeografía.

- Propone un mapa general de relación biótica mundial.

Donn E. Rosen, Norman I. Platnick, Gareth Nelson, Joel Cracraft, Christopher J. Humphries, entre otros (punto de partida: Nelson y Platnick, 1981, 1984)

Robin Craw, John Grehan, Michael Heads, Ian Henderson, entre otros (punto de partida: Craw 1988; Craw et al. 1999)

Juan J. Morrone y Jorge V. Crisci (punto de partida: Crisci y Morrone, 1992; Morrone y Crisci, 1995; Crisci

- Toman algunos fundamentos de la panbiogeografía de Croizat (1958) y otros de la sistemática filogenética de Hennig (1950), y proponen una escuela híbrida en biogeografía histórica, conocida como biogeografía de la vicarianza-cladística. Para esta escuela es fundamental la determinación de áreas de endemismo y conocer la filogenia de los grupos a estudiar.

- Retoman los principios de la panbiogeografía de Croizat (1958) de una manera más pura y utilizan un método basado en la teoría de grafos. Para ellos la monofilia de los grupos a estudiar no es indispensable para la reconstrucción biogeográfica.

- Utilizan un método integrativo que incluye varios aspectos de diferentes corrientes de pensamiento dentro de la biogeografía histórica. 
Cuadro 3. Algunos de los trabajos más importantes sobre fitogeografía de México (exceptuando los de J. Rzedowski)

\begin{tabular}{lll}
\hline \multicolumn{1}{c}{ Autor } & \multicolumn{1}{c}{ Propuestas más importantes } \\
\hline $\begin{array}{l}\text { Humboldt y } \\
\text { Bonpland (1805) }\end{array}$ & - & $\begin{array}{l}\text { Pioneros en mencionar algunas afinidades florísticas de México. } \\
\text { Son los primeros en mencionar las semejanzas florísticas entre los bosques de las } \\
\text { partes altas de México con los Estados Unidos y Canadá. }\end{array}$ \\
Fournier (1881) & - $\begin{array}{l}\text { Encuentra que el } 50 \% \text { de las especies de gramíneas que se hallan en México son } \\
\text { endémicas y la otra mitad se comparte con América del Sur y las Antillas. }\end{array}$ \\
- & La flora de México está formada por elementos de afinidades diversas. \\
Engler (1882) & - La flora de las zonas calientes de México es de afinidad meridional. \\
& - $\begin{array}{l}\text { La flora de las zonas altas comparte muchos elementos con América del Norte y los } \\
\text { - México tiene gran riqueza de elementos con distribución restringida. }\end{array}$
\end{tabular}

Hemsley (18861888)

Watson (1890)

Fernald (1931)

Mc Vaugh (1943)

Gadow (1907-1909)

Trelease (1924)

Standley (1936)

Sharp (1945,

1946a, 1946b)

Sharp et al. (1950)

Hernández-X. et al.

(1951)

Crum (1951)

Leopold (1950)

Miranda y Sharp (1950)

Steyermark (1950)
- Da la discusión más completa sobre las relaciones geográficas y posibles orígenes de la flora de México. Sus principales conclusiones son:

1) La flora de México se caracteriza por su gran diversidad y riqueza.

2) Los géneros endémicos al país son aproximadamente el $11 \%$ del total.

3) La mitad meridional de México es florísticamente más rica que la septentrional.

4) Hay un mayor número de taxones comunes con América del Sur y en orden decreciente con las Antillas, oeste de Estados Unidos y este de Estados Unidos.

5) La flora del sur de México tiene más en común con la del este de Estados Unidos; en cambio la flora del norte la tiene con la del oeste de Estados Unidos.

6) También tiene relación con la flora del este de Asia, África y las Galápagos.

7) El norte de México ha sido centro de origen de la flora xérica.

8) Hay zonas de México que se caracterizan por su mezcla de elementos boreales y meridionales.

9) Advierte la semejanza florística entre los géneros del este de Estados Unidos y sur y este de México, algunos con las mismas especies como Liquidambar. Nota también su ausencia en el oeste de Estados Unidos.

- Advierten las relaciones entre la flora mexicana y la del este de Estados Unidos.

- Distingue 3 componentes principales en la flora mexicana: meridional, boreal y endémico.

- De los 1200-1500 msnm se encuentra la mayor cantidad de especies meridionales; a los 2100 msnm se registra el máximo de afinidad boreal.

- Distingue 7 áreas de distribución con base en la revisión de las especies americanas de encinos.

- Discute las relaciones geográficas de la flora mexicana; reconoce 6 regiones botánicas bien delimitadas: 1) desiertos del norte y centro; 2) península de Baja California; 3) Sierra Madre Occidental; 4) selvas; 5) península de Yucatán y 6) zonas alpinas.

- Se percatan de la semejanza de los bosques del este de Estados Unidos con los del este y sur de México-Guatemala.

- Observan que en los bosques del sur y este de México, localizados en la zona de transición entre la tierra caliente y la templada, las especies de afinidad tropical predominan numéricamente, pero las boreales constituyen casi siempre las dominantes de la comunidad. Se percatan del hiato de 800-1000 km que constituye el este de Texas a San Luis Potosí para estas comunidades boscosas.

- Da cuenta de las semejanzas entre Guatemala y el este de Estados Unidos; opina que los elementos templados provinieron del norte desde fines del Cretácico-principios del Terciario. 
Cuadro 3. Continúa

Autor Propuestas más importantes

Crum (1951) - Los elementos templados provenientes de América del Norte deben de haber llegado

Dressler (1954) a México después, durante el Pleistoceno.

Sharp (1953a, 1961)

Sharp (1953b)

Observa la presencia del elemento asiático en la flora del sur y este de México.

- Discute las afinidades y posibles orígenes de la flora de México:

1) la vegetación templada se originó hasta fines del Plioceno-Pleistoceno.

2) la vegetación tropical es la más antigua en México.

Braun (1955)

Martin y Harrell

(1957)

3) hay una mayor proporción de familias de distribución tropical que de templadas.

Axelrod (1960)

Puig (1968)

- Los elementos templados provenientes de América del Norte deben haber llegado a México antes, durante el Terciario Medio o antes.

- Los elementos templados provenientes de América del Norte llegaron a México durante el Eoceno, Paleoceno y Cretácico.

- Distingue 3 grupos florísticos en la vegetación de la Sierra de Tamaulipas: uno relacionado con la flora de América Central y del Sur (meridional), otro estrechamente ligado con la flora del norte y sur de Estados Unidos (endémico a estas regiones) y otro relacionado con la flora del norte (boreal).

Delgadillo (1971)

- Agrupa los musgos de las zonas alpinas de México en 5 conjuntos, con base en su distribución: norteño, mesoamericano, sureño, de amplia distribución y endémico. Supone que estos taxones migraron a México por las principales cadenas montañosas durante el Plio-Pleistoceno.

Graham (1972)

- Ofrece algunos aspectos de la historia de la vegetación del Terciario en la cuenca del Caribe con base en datos paleobotánicos. Para México sustenta que las comunidades miocénicas de Veracruz son muy comparables a la vegetación actual y que contienen un elemento templado disyunto con el este de Estados Unidos.

Guzmán (1973)

- Estudia las relaciones entre las micofloras de México y el este y oeste de Estados Unidos. Observa que son más fuertes éstas entre las especies de los bosques de coníferas principalmente del norte de México con los bosques equivalentes del noroeste de Estados Unidos, así como las especies de los bosques deciduos del este de Estados Unidos y este de México.

Puig $(1974,1976$, 1989)

- Determina las afinidades florísticas en el nivel de familia de las plantas de la Huasteca y Gómez Farías, Tamaulipas con base en Sharp (1953b) y en el nivel de especie determina los siguientes grupos:

1) Flora tropical: neotropical, neotropical caribeño, neotropical mesoamericano, neotropical mexicano, neotropical mexicano de afinidad este-oeste, neotropical de México oriental, tropical de montaña, andino, africano, asiático y pantropical.

2) Flora boreal: holártico del este de México y este de Estados Unidos, holártico común a México y sur de Estados Unidos; holártico de México y norte de América Central; holártico mexicano y holártico de México oriental.

3) Flora endémica de zonas áridas: endémico del norte de México y sur de los Estados Unidos; endémico del NE de México y sur de Estados Unidos; endémico del NE de México, endémico del N de México y endémico del centro de México.

Graham (1979)

- Propone un modelo de migraciones cenozoicas a través de Mesoamérica. Supone la existencia de un archipiélago que mantuvo con cierto contacto a Yucatán y Cuba. Durante la mayor parte del Terciario existió una faja continua de tierra desde el sur de Estados Unidos y zona del canal de Panamá, que permitió la migración de biotas. Con base en las edades de los fósiles puede encontrar la dirección de la dispersión.

Delgadillo (1979)

- Agrupa a los musgos del bosque de Liquidambar mexicano en 8 elementos fitogeográficos de acuerdo con su distribución. Cuatro de estos grupos son estrictamente mexicanos ( $70 \%$ del total). La flora de musgos de esta comunidad es el resultado de migraciones en diferentes tiempos a través del puente centroamericano y arco antillano y está constituida por una mezcla de especies tropicales y templadas. 
Cuadro 3. Continúa

\begin{tabular}{ll}
\hline \multicolumn{1}{c}{ Autor } & \multicolumn{1}{c}{ Propuestas más importantes } \\
\hline Gentry (1982) & $\begin{array}{l}\text { Opina que el intercambio de especies de plantas entre América del Norte y Sur ha } \\
\text { sido el factor más importante en la determinación de los patrones fitogeográficos } \\
\text { neotropicales actuales. }\end{array}$ \\
Delgadillo (1986) & $\begin{array}{l}\text { Los musgos de las zonas bajas de México migraron de América del Sur a América } \\
\text { del Norte y viceversa desde el Cretácico, conforme fueron emergiendo las tierras; los } \\
\text { musgos de zonas altas lo hicieron más tarde, en el Plio-Pleistoceno. Las disyunciones }\end{array}$ \\
& $\begin{array}{l}\text { entre México y América del Sur se deben a eventos de dispersión a larga distancia. } \\
\text { Ha habido intercambio florístico entre las áreas alpinas de la Faja Volcánica } \\
\text { Transmexicana, lo que puede demostrarse por sus especies compartidas. También } \\
\text { existen especies de distribución restringida. Opina que la Faja ha sido barrera } \\
\text { efectiva para la dispersión de musgos de norte a sur, pero no de sur a norte. Los } \\
\text { musgos del sur debieron migrar al norte antes del levantamiento de las montañas. El } \\
\text { intercambio entre norte y sur debe haberse llevarse a cabo mediante corredores. }\end{array}$ \\
&
\end{tabular}

José Luis Villaseñor y colaboradores (Delgadillo et al. 2003; Villaseñor 2003; EspinosaGarcía et al. 2004; Méndez-Larios et al. 2004; Villaseñor 2004; Villaseñor y Espinosa-García 2004; Villaseñor et al. 2005a,b; Villaseñor et al. 2006)

Ken Oyama,

Daniel Piñero, Luis Eguiarte, Susana Magallón, Judith Becerra (punto de partida: Avise, 1998)

Juan J. Morrone, Isolda Luna, Raúl Contreras, Othón Alcántara, David Espinosa (punto de partida: Morrone y Crisci, 1995)
- Llevan a cabo estudios de diversidad de la flora mexicana en todo el país, en nivel de los grupos superiores o determinadas familias seleccionadas, así como de diferentes estados o regiones. Algunos de los temas principales que cubren son:

1) Determinación de hotspots basados en la distribución de compuestas en la Faja Volcánica Transmexicana. 2) Diversidad de Magnoliophyta y su distribución en México. 3) Determinación de Magnoliophyta endémicas al Valle de TehuacánCuicatlán. 4) Listado de géneros de plantas vasculares presentes en la flora de México. 5) Patrones geográficos de plantas exóticas y malezas en el país. 6) Riqueza y representación de familias varias (i.e. Asteraceae) en México y en algunas provincias florísticas.

- Mediante técnicas moleculares se encuentran los centros de origen de taxones individuales y se proponen historias de dispersión. Representado por corrientes como la filogeografía, reloj molecular y fechación.

- Utilizan un método integrativo que incluye varios aspectos de diferentes corrientes de pensamiento dentro de la biogeografía histórica (panbiogeografía, biogeografía de la vicarianza y análisis de parsimonia de endemismos). de su flora, y 3) hipotetizar escenarios de cómo se llevó a cabo la dispersión de los elementos de la flora, esto es, si se llevó a cabo mediante puentes, filtros, corredores, rutas al azar, dispersión a larga distancia, entre otros, para llegar a ocupar las áreas que ahora habitan.

Rzedowski (1965) reconoció 2 periodos de relativo auge en los estudios fitogeográficos de México: el primero comprende las últimas 3 décadas del siglo XIX, teniendo como exponente máximo a W.E. Hemsley; el segundo va de 1945 a la fecha, y fueron Faustino Miranda y Aaron J. Sharp los iniciadores de este periodo. En su trabajo de 1965, Rzedowski sostuvo que la fitogeografía dista mucho de ser una rama científica independiente y que son raros los botánicos que se dedican exclusiva o principalmente a tal actividad. En México, la mayor parte de las contribuciones en este campo se debe a taxónomos, ecólogos, paleontólogos y fitosociólogos; su trabajo generalmente consta de capítulos o breves discusiones anexas a floras 
Cuadro 4. Contribuciones más importantes de J. Rzedowski a la fitogeografía mexicana

\begin{tabular}{|c|c|}
\hline $\begin{array}{l}\text { Rzedowski } \\
(1963)\end{array}$ & $\begin{array}{l}\text { - La flora del bosque tropical siempreverde es de afinidad neotropical y está muy relacionada } \\
\text { con su equivalente del sureste de México y América Central. }\end{array}$ \\
\hline $\begin{array}{l}\text { Rzedowski } \\
\text { (1972b) }\end{array}$ & $\begin{array}{l}\text { - Revisa las tendencias de la distribución geográfica y ecológica de las compuestas } \\
\text { mexicanas y sustenta que: } \\
\text { 1) están poco diversificadas en zonas bajas y calientes; alcanzan su mayor diversificación } \\
\text { en zonas áridas y en las montañas; 2) las zonas perturbadas o en alguna etapa de sucesión } \\
\text { son generalmente ricas en compuestas; 3) las Heliantheae (Asteraceae) son la tribu más } \\
\text { diversificada en el país y se originaron posiblemente en regiones templado-cálidas; por otro } \\
\text { lado, las Helenieae se originaron en zonas de clima árido; 4) por la extrema diversidad de } \\
\text { compuestas en zonas de montaña y áridas, debe interpretarse que esas zonas son antiguas. }\end{array}$ \\
\hline
\end{tabular}

Rzedowski (1973)

Rzedowski (1975)

González y

Rzedowski (1984)

Rzedowski (1990)

Rzedowski (1962, 1972a, 1991a,b, 1992, 1994, 1996, 2005)
- Estudia las relaciones geográficas de la flora de zonas secas de México. Resuelve que las afinidades con el sur son las dominantes y que existe evidencia para creer que los xerófitas mexicanas derivaron independientemente de la mayoría de sus contrapartes en el oeste de Estados Unidos.

- Analiza fitogeográficamente los pastos mexicanos.

- Analiza las afinidades geográficas de los pastos del Valle de México y sostiene que tienen una afinidad primordialmente neotropical; el 30\% de éstos son de distribución restringida.

- Advierte la existencia en la flora mexicana de plantas introducidas de origen africano, principalmente gramíneas.

- El endemismo en México está favorecido por: 1) larga permanencia de la región en calidad de tierra emergida; 2) cambios climáticos y fisiográficos en el tiempo; 3) aislamiento ecológico; 4) alta diversidad fisiográfica; 5) alta intensidad de evolución.

- $\quad$ El mayor porcentaje de endémicos son hierbas y arbustos perennes.

- Cactáceas, rubiáceas y compuestas (asteráceas) son las familias con una mayor proporción de endémicos (70\% de éstas).

- Las familias endémicas de México son: Canotiaceae, Fouqueriaceae, Pterostemonaceae, Plocospermataceae y Simmondiaceae; todas son propias de zonas áridas.

- A mayor cantidad de aridez, mayor cantidad de géneros endémicos. En nivel de especie sucede lo mismo en las áreas templado semihúmedas.

- La porción septentrional del país es el centro de origen de taxones adaptados a la aridez.

- Hay una mayor proporción de géneros endémicos en matorrales xerófilos y pastizales.

- Propone que los desiertos mexicanos son antiguos, a diferencia de lo que opina Axelrod (1979) quien sugiere que son sumamente recientes (Pleistoceno).

- Clasifica a los endemismos mexicanos en: 1) de una sola localidad; 2) de una región fisiográfica; 3) de todo el país; 4) de islas verdaderas y 5) de islas continentales, esto es: a) zonas áridas, b) zonas montañosas y c) zonas bajas.

- A mayor proporción de aridez, mayor cantidad de géneros endémicos. En el nivel de especie sucede lo mismo en las áreas templado-semihúmedas.

- La distribución de los organismos hace caso omiso de las divisiones políticas; está más bien ligada con la delimitación de regiones naturales definidas por condiciones fisiográficas y de otro tipo. Por lo anterior, Rzedowski extiende las fronteras del país a lo que el llama Megaméxico 1, 2 y 3.

- Por su situación geográfica, México ha tenido una importancia estratégica, pues su territorio constituye el camino más factible para el traslado de organismos terrestres de América del Sur a América del Norte y viceversa. Como consecuencia de estas migraciones de flora y fauna, entre los elementos geográficos que forman parte de su biota actual 
Cuadro 4. Continúa

prevalecen los meridionales y los boreales. Opina que las relaciones con Asia y África son significativas, aunque indirectas; al oriente del país, Yucatán tiene relaciones significativas con las Antillas y al occidente no existe ningún cuerpo terrestre cercano para ejercer una influencia notable en la composición florística de México.

- En Megaméxico 1 hay 4 familias, $10 \%$ de los géneros y 52\% especies endémicos; en Megaméxico 3 hay 5 familias, 17\% de los géneros y $72 \%$ de las especies son endémicos.

- La riqueza de México se debe a la gran cantidad de regiones existentes que funcionan como islas ecológicas.

- $\quad$ Siguiendo a Hemsley y Gadow, reconoce en la flora mexicana 3 elementos geográficos primordiales: meridional, boreal y endémico.

- $\quad$ Las fluctuaciones climáticas del Pleistoceno pudieron haber contribuido en la diversificación de la flora, pero que sus rasgos fundamentales estaban ya bien establecidos mínimamente desde el Terciario Medio.

- La flora del país está compuesta por aproximadamente 220 familias, 2410 géneros y 20000 especies de fanerógamas.

- Los grupos taxonómicos mejor representados pertenecen a las familias Compositae (Asteraceae), Leguminosae (Fabaceae), Gramineae (Poaceae), Orchidaceae, Cactaceae y Rubiaceae.

- México ha sido centro de origen y desarrollo de un gran número de linajes vegetales.

- La mayor concentración de la diversidad se encuentra a lo largo de un área que inicia en Chiapas, incluye Oaxaca, se prolonga por un lado hacia el centro de Veracruz y por el otro a Sinaloa y Durango.

- Las afinidades geográficas de la flora de México son 4 veces más importantes con el sur que con el norte. Esta mayor vinculación con el sur se debe a que la mayor parte de México está ubicado en el reino neotropical.

- Las características fundamentales de la flora estaban ya bien establecidas desde el Terciario medio o antes.

- México junto con América Central constituyen una de las regiones en donde se concentra la mayor diversidad de plantas.

- En México se presentan prácticamente todos los tipos de vegetación existentes en el planeta además de una gran variedad de formas biológicas.

- Revisa las afinidades geográficas de los bosques riparios de México.

- Lleva a cabo un análisis de la flora vascular de los bosques mesófilos de montaña mexicanos.

o estudios de vegetación. Según este autor, la mayoría del trabajo deriva de revisiones de ciertos grupos y pocos estudios están dedicados exclusivamente al problema.

El trabajo de J. Rzedowski en la biogeografía de plantas de México ha sido el más cuantioso y ha estado dedicado principalmente al estudio del conocimiento de la clasificación espacial de la biota mesomericana. Este autor ha hecho varias contribuciones, entre las que destacan aquellas sobre el origen del elemento endémico y las relaciones geográficas y posibles orígenes de la flora mexicana. En resumen, el autor concluye que el $17 \%$ de los géneros de plantas y el $72 \%$ de las especies son endémicas de Megaméxico 3 (incluyendo el sur de Estados Unidos y norte de América Central); que el endemismo de la flora de México es muy grande, pero que no se equipara al de países como Australia o Sudáfrica; que hay una mayor proporción de géneros endémicos conforme aumenta el grado de aridez; asimismo, de especies en climas templado-semihúmedos; que la mayor cantidad de géneros endémicos están mejor representados en la mitad 
septentrional del país y son más abundantes en la vertiente pacífica que en la atlántica (Cuadro 4).

\section{Las hipótesis biogeográficas y la biota de México}

Dispersalismo. A partir del planteamiento dispersalista, una primera explicación causal de por qué tiene México tantas especies se basa en el hecho de que se localiza en la transición entre 2 regiones biogeográficas (Fig. 2). La mezcla de sus floras y faunas genera patrones interdigitados en los que se observa el avance de los grupos neotropicales hacia el norte por las tierras bajas, mientras los neárticos avanzan hacia el sur a través de las grandes cordilleras mexicanas. Ésta ha sido la manera como se ha explicado la presencia del elemento boreal en México, generalmente mediante un proceso de dispersión a través de las montañas. Se ha considerado que las cordilleras han servido de puente o corredor, sobre todo en aquellos casos en que las montañas tienen la suficiente elevación para mantener condiciones equivalentes para el paso y supervivencia de plantas que requieren condiciones climáticas frías, v. gr. muchos de los árboles dominantes o codominantes en los bosques templados mexicanos como Carpinus, Clethra, Cornus, Pinus y Liquidambar, entre otros. Para Graham (1973) los tipos de vegetación con afinidad boreal fueron penetrando hacia el sur del continente americano durante el Terciario y Cuaternario; muchos otros autores han sostenido diferentes épocas de arribo de estos elementos, v. r. Cenozoico medio, Cenozoico superior o incluso Pleistoceno. Se ha recurrido al puente de Bering para explicar su posible parentesco con la flora templada del este de Asia, como se postulaba hace más de un siglo.

El arribo de plantas con origen sureño, sobre todo de elementos templados, no ha podido explicarse tan

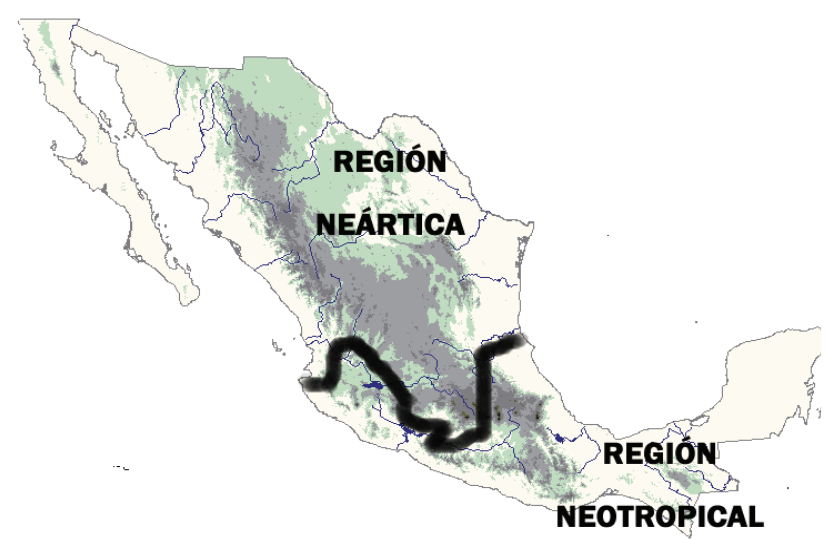

Figura 2. Posición estratégica de México entre 2 regiones biogeográficas. Bajo el enfoque dispersalista, se considera que México tiene un número elevado de especies en virtud de su ubicación biogeográfica, en la transición de las regiones neártica y neotropical. claramente como el caso de los elementos templados del norte (v.gr.Weinmmania y Zinowewia). Una de las ideas más aceptadas es que el puente centroamericano se ha elevado más de una vez y que en diferentes tiempos ha dejado pasar ciertos elementos de un lugar a otro. Por ejemplo, Graham (1979) propone que durante la mayor parte del Terciario existió una franja más o menos continua de tierra desde el sur de Estados Unidos hasta Panamá por donde se llevó a cabo el paso de plantas y animales; asimismo, explica el paso de organismos de las Antillas a América continental mediante la existencia de un "archipiélago" que redujo en parte la discontinuidad terrestre entre Yucatán y Cuba.

Las grandes disyunciones en la biota de México han llamado la atención de los botánicos desde hace mucho tiempo. Por ejemplo, Martin y Harrell (1957) y Martin (1958) observan que en las montañas del este de México y este de Estados Unidos existen plantas y animales emparentados cercanamente, pero que su distribución es disyunta, esto es, que no se encuentran en la zona intermedia constituida por la zona desértica de Texas y zonas bajas adyacentes (Fig. 3). Asimismo, explican que esto puede deberse a 2 diferentes causas, ambas en el contexto de la biogeografía wallaceana: 1) que las montañas mexicanas hayan funcionado como refugio durante el Pleistoceno para albergar la biota desplazada por los hielos durante la época glaciar, 2) que el elemento templado haya llegado a México a mediados del Cenozoico y se haya vuelto disyunto de su contraparte norteña por el desarrollo de una zona árida en el sur de Texas y noreste de México durante el Pleistoceno. Esta última aseveración, que es la que apoyan en su trabajo, requiere del desarrollo de un corredor de bosque durante el Pleistoceno, o por lo menos de una ampliación del bosque templado, en una zona donde actualmente existe una zona árida, y también de que las condiciones climáticas en esta área hubieran sido más húmedas y frías para poder soportar un corredor con liquidámbares, magnolias, Carpinus y Fagus, entre muchos otros elementos. En cualquiera de los casos se requiere del movimiento de la biota (dispersión) de un sitio a otro, dependiendo de las capacidades de dispersión de cada una de las especies involucradas. Este mismo problema lo abordó Rosen (1978), utilizando como fuente de evidencia un grupo de peces de agua dulce, pero bajo otro tipo de metodología biogeográfica.

La mayoría de los trabajos que han intentado explicar los patrones de distribución de plantas mexicanas han sido gestados bajo el enfoque mencionado anteriormente. Sin embargo, los más recientes han incluido la variante de reconocer que la topología de la Tierra ha cambiado en el tiempo geológico, pero aún así han explicado los patrones de distribución de las plantas por medio de la dispersión en una Tierra dinámica y cambiante, corriente que en este trabajo se reconoce como enfoque dispersalista actualizado 


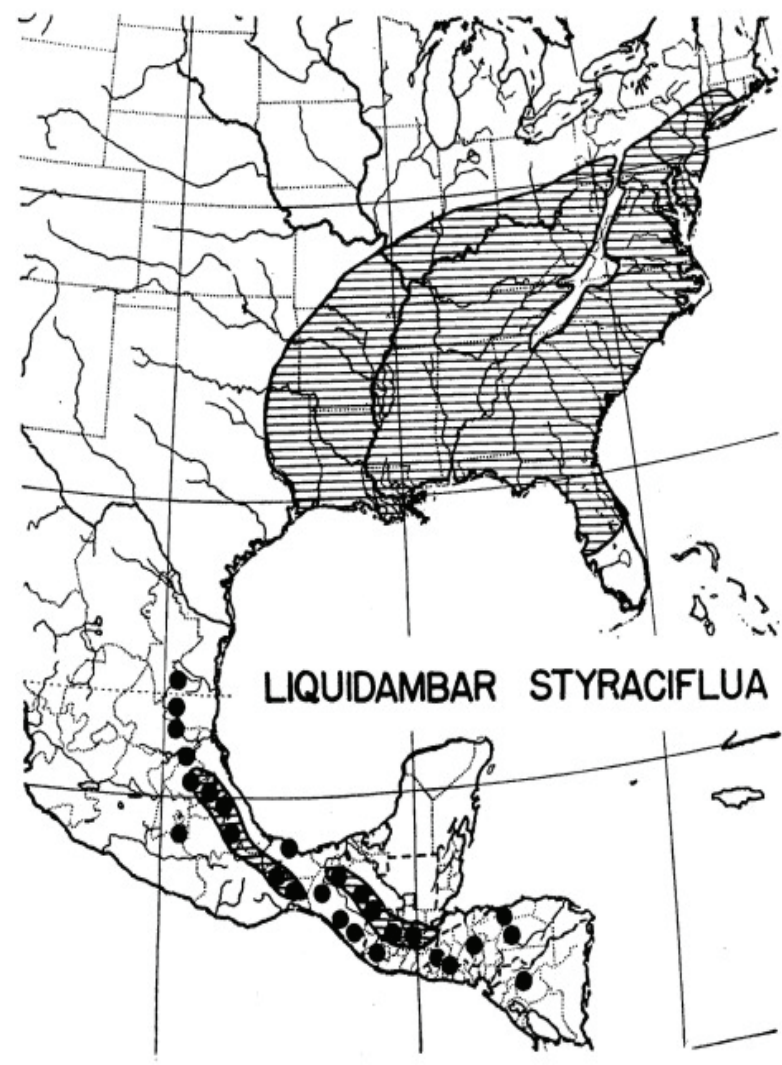

Figura 3. Distribución disyunta de Liquidambar styraciflua en el este de México-este de Estados Unidos. Modificado de Martin y Harrell (1957).

o neodispersalista, como es el caso de la biogeografìa filogenética.

Actualmente está resurgiendo el dispersalismo, como ya lo había detectado Morrone (2002). Este resurgimento está representado en México por enfoques como la filogeografía, el reloj molecular y el fechamiento, corrientes que se abordan someramente más adelante. Algunas de las aportaciones gestadas bajo la corriente dispersalista en México se pueden revisar en los Cuadros 3 y 4.

Se ha sugerido que las distribuciones prueban que los grupos neárticos y neotropicales expandieron sus áreas de distribución sobre territorio mesoamericano, y que estos eventos de expansión repercutieron en el incremento de la diversidad de taxones que hoy vemos en México (Halffter, 1964b; Halffter, 1978; Rzedowski, 1978). Pero la explicación central es aún ambigua. Según el planteamiento original de Darwin (1859) y Wallace (1876), continuado hasta Darlington (1938), las especies no se originaron donde están sino en unos cuantos centros de origen, así, la riqueza florística de México resultaría de la suma de 2 floras diferentes: unas especies llegaron del norte y otras más llegaron del sur. Pero si analizamos grupo por grupo podemos encontrar muchos casos de géneros que tienen su mayor riqueza de especies a lo largo de las diferentes áreas del territorio mexicano con endemismos en estas áreas. La gran cantidad de especies endémicas presentes en México no respalda la idea de la dispersión desde centros de origen. Si las especies proceden de otros lugares, sólo esperaríamos una buena cantidad de elementos de distribución amplia. A menudo se menciona, como una explicación alternativa, la existencia de 2 importantes centros de evolución en México donde se forma una gran cantidad de especies, la mayoría de éstas endémicas: la Faja Volcánica Transmexicana y la Cuenca del Balsas. La principal evidencia de esta propuesta es que los centros de mayor diversidad se localizan justamente en esas 2 grandes áreas (Clausen, 1959; Ceballos y Navarro, 1991; Fa y Morales, 1991; Chávez y Trigo, 1996; TorresMiranda y Luna, 2006).

Biogeografia filogenética. Este enfoque, iniciado con los trabajos de Brundin (1966, 1981), Hennig (1968) y Ball (1976), sólo lo ha utilizado Dávila-Aranda (1991) en un trabajo que tuvo como objetivo principal resolver la filogenia de un grupo de 17 especies de Sorghastrum (Poaceae) presentes en el país y como objetivo secundario proponer una hipótesis biogeográfica para explicar su presencia en México. Mediante este enfoque, se propone el centro de origen para el género y se diferencian las especies más plesiomórficas de las más apomórficas. Se considera un enfoque ecléctico, ya que intenta explicar los patrones generales de distribución mediante vicarianza y los casos excepcionales por dispersión; asimismo, intenta encontrar los centros de origen de los grupos mediante el análisis de cladogramas y propone probables rutas de dispersión a saltos, a través de una Tierra dinámica.

Filogeografia. Avise (1998) ha promovido un enfoque llamado filogeografía. Se define como el análisis espacial de los linajes génicos, aplicado a linajes infraespecíficos o de especies emparentadas cercanamente.

Dado que los haplotipos o variantes del DNA mitocondrial registran una historia matrilineal de eventos mutacionales, es posible conectarlos de un modo filogenéticamente inteligible en un filograma, el cual se superpone con la distribución geográfica del grupo en estudio. Ronquist (1997) opina que la filogeografía es un acercamiento a la biogeografía histórica a una escala ecológica de tiempo. Para algunos autores la filogeografía o biogeografía del gen es una versión moderna del dispersalismo (Morrone, 2002), mientras que para otros es una alternativa al mismo (Piñero, 2002, Delgado y Piñero, 2002; Cuenca et al., 2003). La filogeografía explícitamente 
acepta tanto la dispersión como la vicarianza, pero invariablemente los patrones observados se explican mediante dispersión.

La filogeografía puede abordar los aspectos filogenéticos de la distribución espacial de cualquier característica; sin embargo, en la actualidad se basa principalmente en el análisis de DNA del cloroplasto para el caso de las plantas.

Los estudios filogeográficos aplicados a plantas mexicanas se han llevado a cabo principalmente en el Instituto de Ecología, UNAM y en el Centro de Investigaciones en Ecosistemas, UNAM, por los grupos de trabajo de D. Piñero (filogeografía de coníferas, en especial pinos, Pinus strobiformis, además de hongos, cactáceas y musgos; Cuenca et al., 2003; Delgado y Piñero, 2002), K. Oyama (encinos y cactáceas), L. Eguiarte (principalmente pinos) y C. Domínguez (Oxalis alpina). También han sido abordados por J. Becerra de la Universidad de Arizona, principalmente con Bursera (Becerra, 2005).

Reloj molecular y fechamiento. Esta corriente inicia con los trabajos de M. Lavin y colaboradores (Lavin et al., 2004, 2005; Renner 2004, 2005). En México la siguen investigadores del Instituto de Biología, UNAM, en particular el grupo de A. Delgado. La idea central de estos autores es que frecuentemente las filogenias datadas de familias de plantas de distribución global indican que fue la dispersión, aun a través de los océanos, más que la tectónica de placas, el proceso que ha propiciado su amplia distribución. Los seguidores de esta corriente opinan que la tectónica ocurrió hace mucho tiempo y por lo tanto no afectó taxones que han tenido una radiación reciente. El trabajo de Montero (2006) sobre un grupo de especies pertenecientes al género Phaseolus (Fabaceae) estimó el tiempo de divergencia del mismo basado en estudios de DNA, reloj molecular y fechamiento, y concluye que la distribución actual de este grupo de especies puede explicarse mejor por dispersión, dado que el grupo es más joven que la tectónica.

Esta nueva corriente sustenta que la evidencia molecular sugiere que la dispersión a larga distancia ha desempeñado un papel central en el establecimiento de las distribuciones actuales de muchas familias de plantas, sobre todo las de amplia distribución mundial, como Lauraceae, Fabaceae, Annonaceae, Burseraceae, Melastomataceae, Malpighiaceae y Moraceae. Se argumenta que en estas familias, la mayoría de las disyunciones continentales tienen dataciones muy recientes, como para poder explicarse por tectónica.

En el Instituto de Biología, UNAM se llevan a cabo trabajos utilizando métodos paleontológicos y moleculares. Susana Magallón fechó algunos grupos de angiospermas y analizó sus implicaciones biogeográficas (Magallón, 2004), con lo cual se puede inferir la localización del centro de origen de ciertos grupos de plantas y proponer su posible dispersión a los lugares que actualmente ocupan.

Vicarianza. En los últimos 50 años, la teoría de la deriva continental provocó que muchos biogeógrafos aceptaran que la distribución de los organismos también puede explicarse por vicarianza, fenómeno que provocó un paulatino abandono de algunas hipótesis dispersalistas, al menos para explicar los grandes patrones de distribución de la biota cenozoica.

Un primer trabajo sobre la distribución disyunta de especies mexicanas fue realizado por Rosen (1978) con un grupo de peces, tratando de abordar el mismo problema que Martin y Harrell (1957) hicieran con otros taxones, pero con base en una explicación dispersalista. En un trabajo pionero en su tipo para México, Rosen (1978) planteó que la distribución disyunta de estos vertebrados se debe a un proceso de vicarianza, más que a un evento de dispersión, y que varios grupos de seres vivos muy alejados filogenéticamente presentan distribuciones coincidentes, conformando un patrón general. Rosen sugiere que los componentes separados de este patrón están conectados históricamente entre ellos mismos y con la historia geográfica; observa que son muchos los grupos con una distribución disyunta pero congruente (peces, reptiles, mamíferos, plantas), con modos de dispersión totalmente diferentes, cuyas distribuciones pueden sobreponerse en un mapa mostrando un patrón general (Fig. 4), lo que le hace suponer que estos grupos tenían en el pasado una distribución más amplia que fue fragmentada por algún accidente geográfico. La suposición de Rosen, a diferencia de la de Martin y Harrell (1957), no requiere formular escenarios de difícil comprobación, sólo de conocer la historia geológica de América del Norte.

Los enfoques vicariantes se fundamentan metodológicamente en una estrecha relación entre la sistemática y la biogeografía. La idea central que subyace a estos enfoques es que la evolución opera conjuntamente en forma y espacio a través del tiempo, por lo tanto, es posible a partir de la historia evolutiva de los grupos taxonómicos inferir la historia evolutiva de las áreas de distribución (como lo plantean la panbiogeografía y la biogeografía cladística), e incluso los patrones biogeográficos pueden revelar nexos evolutivos entre los taxones (como lo propone la panbiogeografía). A veces, los enfoques panbiogeográfico y cladístico dan diferente peso a los modelos geológicos como evidencia o recurso para preferir uno u otro modelo de interrelación biogeográfica. Para los seguidores de la escuela cladista, la geología sólo ha llegado a resolver el problema de la 


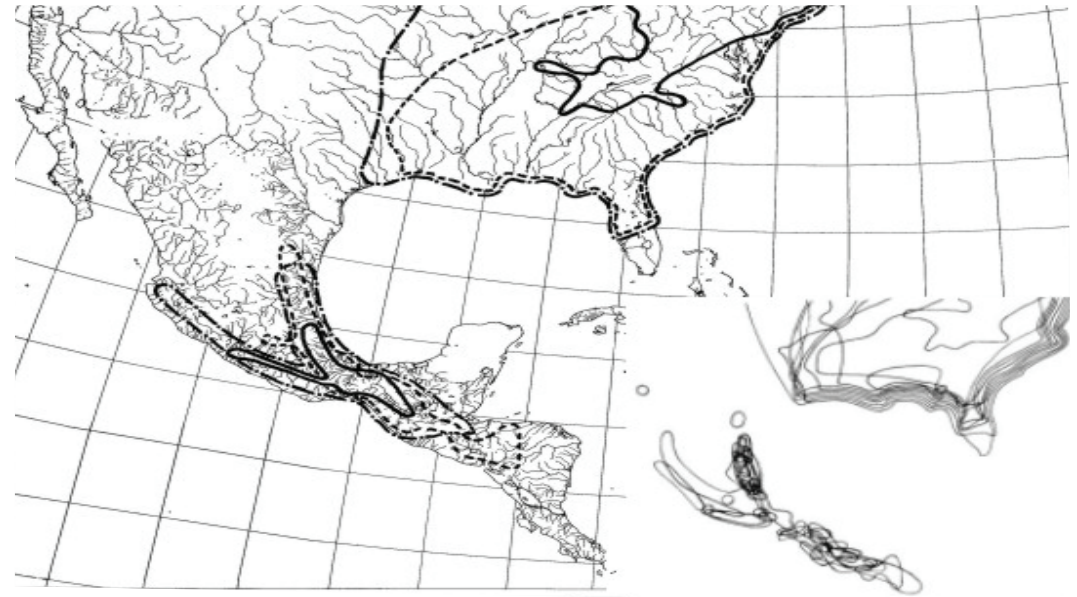

Figura 4. Co-ocurrencia de Pinus strobus, Liquidambar styraciflua y Carpinus caroliniana en el este de Méxicoeste de Estados Unidos. Modificado de Rosen (1978). evidencia de la tectónica de placas y su mecanismo. Pero hoy se encuentra ante el mismo problema que provocó el resurgimiento de la biogeografía: la reconstrucción de la historia. Por ello, la biogeografía cladística sostiene que el análisis biogeográfico debe realizarse al margen de cualquier hipótesis particular de la historia geológica. Por ejemplo, en el caso de la biota caribeña, que se trata más adelante, se tienen al menos 8 modelos geológicos diferentes a contrastar, de manera que decidirse por uno de ellos a priori resultaría restrictivo para el investigador.

La biogeografía histórica de México bajo el enfoque vicariante. Según Morrone (Ebach y Morrone 2005), la panbiogeografía y la biogeografía cladística son parte de la biogeografía de la vicarianza, y ambas tienen como objetivo encontrar homología biogeográfica. La panbiogeografía intenta encontrar homología primaria y la biogeografía cladística homología secundaria. Dentro de este enfoque también podemos englobar el análisis de parsimonia de endemismos y una corriente nueva, que en este trabajo se reconoce como enfoque integrativo. A partir de 1990, empieza a aparecer una serie de trabajos que incluye plantas mexicanas como taxones de estudio utilizando estos enfoques. Algunos comentarios sobre dichos trabajos se ofrecen en los apartados siguientes.

Panbiogeografia. Bajo este enfoque se enfatiza la importancia de la dimensión geográfica para la comprensión de los procesos evolutivos (Craw et al., 1999). El método panbiogeográfico fue desarrollado por Croizat (1958) y ha sido perpetuado hasta nuestros días con el nombre de análisis de trazos, principalmente por autores neozelandeses, argentinos y mexicanos.

El estudio de la distribución de algunas plantas bajo este método se aplicó en México hasta muy recientemente, durante los últimos 7 años. Los únicos trabajos utilizando este enfoque para México son el de Contreras-Medina et al. (1999), Luna y Contreras-Medina (2000), ContrerasMedina y Eliosa-León (2001), Luna y Alcántara (2002), Martínez y Morrone (2005), Andrés et al. (2006) y Torres-Miranda y Luna (2006). Un trabajo más que ocupa herramientas panbiogeográficas es el de Luna et al. (2000), pero dado a que involucra también otras metodologías dentro de la biogeografía histórica, se incluye más adelante dentro del enfoque integrativo.

El método panbiogeográfico o de trazos permite obtener resultados más rápidamente, ya que exige requerimientos mínimos para trabajar. Tiene una amplia potencialidad de aplicación para zonas tectónicamente complejas como es el caso de México, por lo que ha promovido la discusión de las interrelaciones históricas que mantiene la biota mexicana con otras biotas situadas hacia el norte, el sur, el Caribe y con las situadas al otro lado del Pacífico. Hasta hace poco tiempo, el dibujo de los trazos individuales y generalizados se hacía a mano, pero actualmente existe un software llamado Trazos (Rojas-Parra, 2005) que permite obtenerlos de forma automatizada.

México queda incluido en el análisis global de Croizat (1958) como uno de los 5 grandes nodos panbiogeográficos del mundo, que son áreas donde convergen 2 o más líneas de fragmentación biótica-geológica (Fig. 5). Los 5 nodos de Croizat coinciden con las áreas de mayor riqueza de especies en el mundo. Según este mapa de trazos generalizados, México tiene al menos 3 historias tectónicas: neárticas, neotropicales y transpacíficas que produjeron una extraordinaria fragmentación de biotas. Si aceptamos que la Tierra y la biota evolucionan de manera conjunta se entiende por qué México tiene una biota de constitución taxonómica tan compleja o híbrida.

Biogeografía cladística. Como ya se mencionó, el primer intento de esta escuela aplicado a taxones mexicanos, 
fue el de Rosen (1978), pero no con plantas. Este autor propuso un método para inferir relaciones históricas entre biotas a partir de las interrelaciones genealógicas de las especies que las habitan, conocido como método de reducción de cladogramas de área. Este autor trabajó con 2 grupos de especies de peces de agua dulce, pertenecientes a los géneros Xiphophorus y Heterandria, y encontró que cuando se sustituían las especies por las áreas que ocupan en los respectivos cladogramas, al menos se distinguían 3 coincidencias de interrelación histórica, mismas que indicaban la existencia de un área de distribución antigua que se fragmentó en 2 ocasiones y que actualmente constituyen las grandes cuencas de los ríos Bravo, Pánuco y Grijalva.

Otro trabajo pionero para México, tampoco con plantas, es el de Liebherr (1991), quien analizó la historia de la biota de las montañas, a partir la comparación de 2 géneros de coleópteros (Elliptoleus y Calathus). Este autor encontró un patrón de distribución de áreas de endemismo de la biota de montaña que indica que las áreas de endemismo disminuyen de tamaño y aumentan en número hacia el sur de México. La complejidad de la historia geológica del sur de México queda manifiesta en el cladograma general de áreas de Liebherr, el cual indica una fragmentación primaria muy antigua que separa una biota extratropical de otra tropical. El sector extratropical se divide luego en 2 áreas, una sobre la Sierra Madre Oriental y otra que incluye la Sierra Madre Occidental y parte del altiplano mexicano, que a su vez se subdivide en 4 áreas más. El sector tropical, por otra parte, muestra un periodo de fragmentación que involucra 8 áreas montañosas ubicadas sobre los extremos sureños de las Sierras Madre, Oriental,
Occidental, y del Sur y el Escudo Mixteco. Una de esas 8 áreas se subdivide durante el periodo de formación de la Faja Volcánica Transmexicana en 5 áreas diferentes. El cladograma final involucra 17 áreas de endemismo en la biota de montaña de México. Si consideramos la observación hecha por Rzedowski (1992) en el sentido de que la mayor acumulación del endemismo se encuentra en las zonas áridas y semiáridas de México, el problema que le espera a la biogeografía es interesante y complejo. En efecto, a la biota tropical de México se le atribuyen relaciones neotropicales y transpacíficas, ya mencionadas por Croizat (1958), que complican sin duda su resolución.

Bajo este enfoque sólo se han producido 3 trabajos que incluyen plantas mexicanas, los de Contreras-Medina y Luna (2002), Contreras-Medina et al. (2007a) y Espinosa et al. (2006), los 2 primeros analizando la distribución de algunas gimnospermas y el tercero con Bursera. Dado a que se requiere de las filogenias completas de los taxones a estudiar, es un método que no se ha utilizado tanto como la panbiogeografía y el análisis de simplicidad de endemismos. Para la mayoría de las plantas mexicanas todavía no existen tales estudios, lo cual limita su aplicación.

Análisis de parsimonia de endemismos. Luna et al. (1999) y Morrone (en Ebach y Morrone, 2005) sugieren que el análisis de parsimonia de endemismos o PAE (por sus siglas en inglés: parsimony analysis of endemicity) es una técnica panbiogeográfica cuantitativa ya que, como la panbiogeografía, intenta identificar homología primaria; no obstante, para fines prácticos, este método se discute aparte.

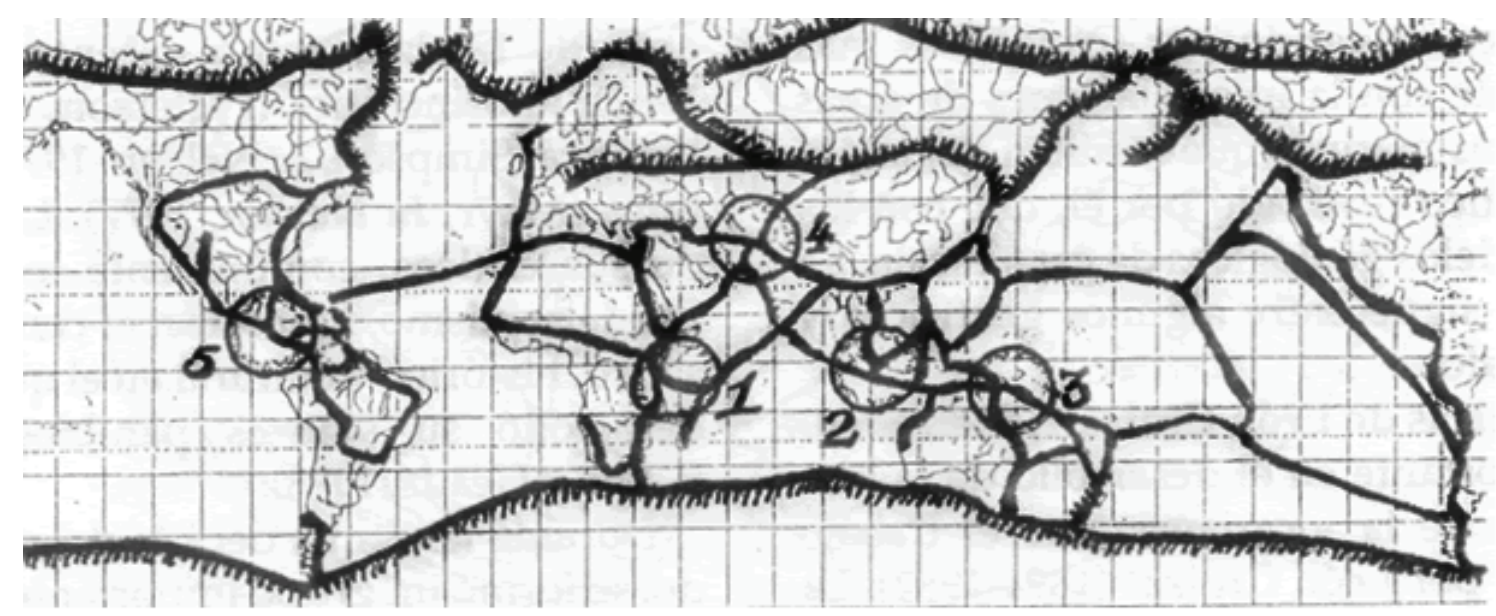

Figura 5. Trazos generalizados y nodos panbiogeográficos (1-5) propuestos por Croizat (1958), donde se muestra la naturaleza compuesta de la biota mesoamericano-caribeña en la que se ubica México. 
El primer trabajo llevado a cabo con este enfoque para organismos mexicanos fue el de Luna et al. (1999); a partir de éste, se generaron al menos una decena de trabajos con otros grupos, v. gr. aves, mamíferos, anfibios, reptiles, helmintos, insectos y hongos. Este trabajo y el de Luna et al. (2001), intentan explicar las relaciones biogeográficas de los bosques templados de montaña mexicanos y neotropicales con base en la distribución de plantas vasculares. Otros trabajos que incluyen como taxones de estudio plantas mexicanas son los de Morrone et al. (1999), Espinosa et al. (2001) y Méndez-Larios et al. (2005) con angiospermas varias, el de Dávila-Aranda et al. (2002) con cactáceas, y el de Contreras-Medina et al. (2007b) con gimnospermas.

Según Humphries y Parenti (1999), Humphries (2000) y Brooks y Van Veller (2003), el PAE no debe considerarse un enfoque dentro de la biogeografía histórica, sino un método más bien fenético. El resultado del PAE es un cladograma de áreas, generado a partir de las localidades muestreadas (de la misma manera que cuando en la biogeografía cladística se trabaja con áreas de endemismo), mismas que son analizadas con base en las especies que contienen, sin requerir de filogenias de los taxones involucrados. Asimismo, al igual que en algunos métodos de la biogeografía cladística, utiliza el criterio de parsimonia para obtener un cladograma final de áreas (Contreras-Medina, 2006).

Método integrativo. El uso de diferentes métodos biogeográficos de una manera integral permite maximizar las bondades metodológicas de cada uno de ellos (Morrone y Crisci, 1995). Las bondades de combinar varias técnicas de diferentes metodologías en un mismo análisis biogeográfico han sido discutidas por Morrone y Crisci (1995), Crisci et al. (2000), Espinosa y Morrone (2000), Crisci (2001) y Contreras-Medina (2006). Para plantas mexicanas, sólo el trabajo de Luna et al. (2000) ha integrado el PAE con la panbiogeografía para detectar homología espacial y después delimitar áreas de endemismo y/o proponer zonas a conservar. Los beneficios de utilizar diferentes metodologías de manera conjunta son evidentes, ya que cada enfoque intenta responder diferentes preguntas biogeográficas. De esta manera, los estudios biogeográficos deben adoptar un enfoque más integrativo, evitando disputas inútiles, con el fin de resaltar las bondades de cada metodología. En este sentido, Ebach y Morrone (2005) sugieren que la biogeografía actualmente es un conjunto de métodos y procedimientos que se utilizan para responder varias preguntas y objetivos.

Glaciaciones pleistocénicas. Toledo (1976, 1982) sostiene que existen numerosas pruebas de diferente índole (paleoclimáticas, paleoecológicas, palinológicas, entre otras) de que durante el Pleistoceno, muchos países del globo sufrieron de gran inestabilidad climática y ecológica, derivada del avance y retracción de glaciares, provocando cambios severos sobre las comunidades vegetales. Este autor propone que algunas zonas de México y zonas adyacentes de Belice y Guatemala, actuaron como refugios de especies durante las épocas más desfavorables. Estas zonas se caracterizaban porque no fueron afectadas o lo fueron en menor escala por los drásticos cambios del clima durante el Pleistoceno. Para México, Toledo (1982) propone 2 refugios, la región lacandona y la del Soconusco, ambas en Chiapas, que se extienden hacia el sur en América Central y se caracterizan por contener un gran número de especies y un alto endemismo específico o subespecífico (Fig. 6).

Es indudable la influencia de los cambios climáticos ocurridos durante el Pleistoceno en países como México, que según este modelo permitieron el establecimiento de especies de climas fríos, mientras que las especies de climas tropicales se extinguieron en parte de las áreas que ocupaban, por lo que su distribución se restringió a zonas de refugio. Según esta teoría, el aislamiento que sufrieron las especies en estos refugios dio origen al surgimiento de nuevas especies, que cuando los glaciares se retiraban (fenómeno que ocurrió muchas veces de manera cíclica) extendían su área de distribución. Este proceso produjo, según los seguidores de este enfoque, un considerable incremento en el número de especies, por lo que se sugiere que muchas de las que hoy habitan en nuestro país son neoendémicas (esto es, de origen relativamente reciente y endémicas). Los refugios separados de bosque funcionarían como una "bomba" de especiación, a través de un mecanismo de aislamiento (Prance, 1982).

El modelo de los refugios pleistocénicos ha sido severamente criticado. De Souza (1991) propuso mediante modelos matemáticos relativamente sencillos su invalidez; Colinvaux et al. (2000) lo critican con base en comunidades amazónicas de plantas; Cracraft y Prum (1988) han cuestionado que la distribución de algunas poblaciones de aves del Neotrópico haya sido producto de una especiación masiva reciente, y que más bien son resultado de eventos vicariantes que se han llevado a cabo durante mucho tiempo; Willis y Whittaker (2000) y Knapp y Mallet (2003) opinan que el modelo de refugios es simplista y que la especiación en los trópicos no puede ser sólo atribuida a la existencia de refugios, existiendo otros factores que han venido actuando mucho antes del Cuaternario. La mayoría de estos trabajos resumen que la biodiversidad en el Neotrópico ha existido desde mucho tiempo atrás (52 millones de años), antes de las glaciaciones del Pleistoceno (1.64 millones a 10,000 años antes). No obstante, hay otros trabajos generales que 


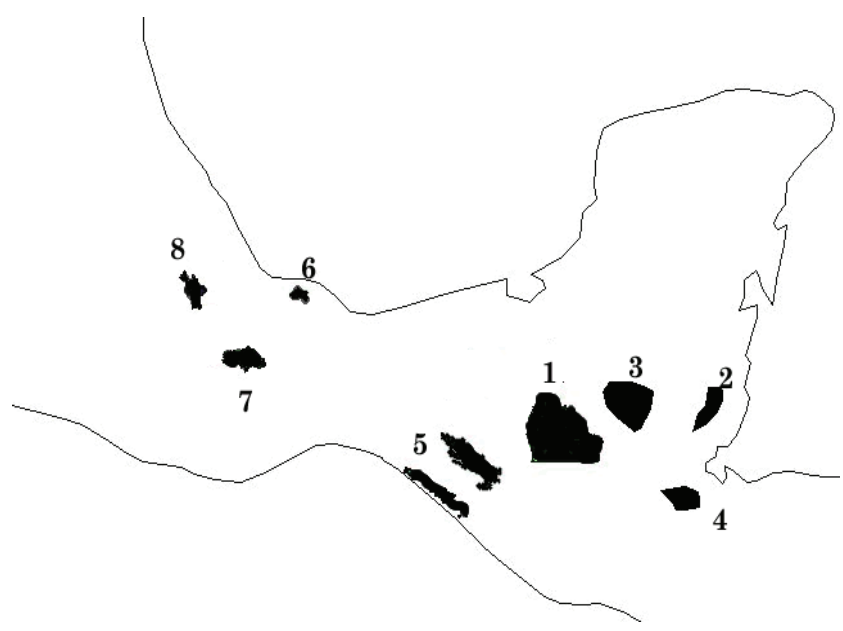

Figura 6. Principales refugios tropicales durante el Pleistoceno. Los refugios primarios son: 1) Lacandonia, 2) Montañas mayas (Belice), 3) Petén (Guatemala), 4) Izabal (Guatemala) y 5) Soconusco. Los refugios secundarios son: 6) Los Tuxtlas, 7) Sierra de Juárez y 8) Córdoba. Figura tomada de Toledo (1976).

apoyan el modelo (Mayr y O’Hara, 1986; Lynch, 1988; van der Hammen y Hooghiemstra, 2000).

En México, la especiación en el trópico se explica mejor por la antigüedad de las barreras (de edad miocenopliocénicas), que no son climáticas sino tectónicas, que por supuestas contracciones y expansiones climáticas. Tal vez, el efecto de los glaciares en México haya producido secuelas más severas en las biotas templadas húmedas de montaña, donde el factor paleoclimático acentúa la vicarianza tectónica. No obstante, se ha sugerido que los refugios han desempeñado un papel importante en la evolución de algunas plantas mexicanas, como es el caso de los géneros Ceratozamia y Pinus (Contreras-Medina, 2006).

Pocos son los trabajos que versan sobre el efecto de las glaciaciones para explicar la distribución de plantas mexicanas; entre ellos están el de Lozano-García (1996), quien opina que gran parte de la diversidad documentada, así como la de los endemismos de la parte central de México, son consecuencia de las oscilaciones climáticas ocurridas durante el Pleistoceno. Otro trabajo reciente es el de Lozano-García y Vázquez-Selem (2005), quienes con base en datos palinológicos y de cronología glacial, documentan un cambio climático y de vegetación en el Holoceno en el Iztaccíhuatl debido a cambios de temperatura y precipitación. Otros trabajos dispersos utilizan este criterio para explicar la distribución de plantas mexicanas, sin que el objetivo principal sea el biogeográfico, generalmente como un apéndice de otros de tipo ecológico o taxonómico.

\section{México y la biota caribeña-mesoamericana}

La historia geológica y de la biota de las Antillas y Mesoamérica representa uno de los principales rompecabezas para la geología y la biogeografía histórica y han sido estudiadas principalmente a partir de los años 70. Los geólogos han propuesto no menos de 7 historias diferentes para las Antillas, mientras que los biogeógrafos han reconocido al menos 5 fuentes de afinidad en la biota antillana: centroamericana-sudamericana, norteamericana, africana, asiática y australiana.

Rosen (1985) distinguió 2 grandes grupos de modelos geológicos en las Antillas. Por un lado los que parten de la formación del golfo de México por un desplazamiento latitudinal pre-Cenozoico que separó América del Norte y América del Suren dirección norte-sur; las Antillas Mayores aparecieron después por eventos geológicos secundarios. Por otro lado, están los modelos geológicos que parten de desplazamientos longitudinales en el Cenozoico temprano en los que los eventos de fragmentación se centran en las Antillas. A pesar de sus divergencias, ambas visiones de la historia de las Antillas coinciden en que: a) hubo un contacto primario entre América del Norte y del Sur por medio de las Protoantillas, b) hubo un desplazamiento longitudinal de las Antillas, c) la isla La Española (o isla de Santo Domingo) es geológicamente híbrida y hubo contacto entre la parte central de La Española y la parte oriental de Cuba, $d$ ) en algún momento hubo contacto o al menos mucha proximidad entre el oriente de Cuba y la Florida y entre el occidente de Cuba y Yucatán, e) el cierre secundario de América Central con América del Sur y el movimiento del bloque Chortis (Honduras y Nicaragua) a lo largo de una falla involucró un cambio de posición considerable respecto a las Antillas (Rosen, 1985).

En cuanto al punto de vista biogeográfico, hay por lo menos 6 intentos importantes de reconstruir la historia de la biota antillana-mesoamericana. Entre los trabajos más importantes se encuentran los de Darlington (1938), Rosen (1975, 1985), Savage (1982), Donnelly (1988), Liebherr (1991) y recientemente el de Morrone (2001). Liebherr (1991) hace una comparación de algunos de los patrones de interrelación biogeográfica que se han obtenido antes con diferentes taxones y genera un cladograma general de áreas que resume los patrones más evidentes de la historia de la biota antillana-mesoamericana. En su análisis destaca las relaciones del sureste de México, en particular de las tierras altas de Chiapas, con el resto de América Central, con el centro y el sur de La Española y con Jamaica, principalmente. De nuevo se destaca el origen geobiótico híbrido de las áreas mexicanas, lo cual representa un tema interesante por investigar. El trabajo de Morrone (2001) es una contribución descriptiva que detalla las regiones, subregiones y provincias biogeográficas de Latinoamérica 
y el Caribe, y discute sus posibles relaciones.

\section{Perspectivas de la biogeografía en México}

La biogeografía histórica y la sistemática en general entraron a una nueva era desde la publicación de Hennig (1950, 1968); este autor dio a la biogeografía histórica un método que evitó la marcada dependencia a la especulación en el trabajo biogeográfico (Brundin, 1988). Las posibilidades creadas por un transporte (pasivo en el caso de las plantas) entre diferentes masas de tierra y a través de los océanos fueron exagerados. En este trabajo se recalca la importancia de los procesos de vicarianza como otra causa fundamental de la distribución presente y pasada de los organismos. Tanto la dispersión como la vicarianza son fenómenos igualmente importantes y posibles de suceder, como lo ha mencionado Crisci et al. (2000).

Cada vez nos percatamos más de la importancia de reconocer y localizar los taxones endémicos para poder conservar la diversidad biológica de México. Comparativamente, la magnitud del endemismo nos sirve para indicar el grado de singularidad de una determinada biota, esto es, cuan diferente es respecto a las biotas de otras zonas del mundo (Rzedowski, 1991a).

El endemismo es un evento histórico (geológico), no ecológico; no es la suma de tiempos ecológicos extensos, ni la prolongación de divergencias extremas. Sin embargo, a mayor cantidad de tiempo y de aislamiento, mayor porcentaje de endemismo, esto es, mayores diferencias cualitativas; por lo tanto, las áreas más antiguas de México contienen una mayor cantidad de endemismos o éstos son más acentuados (paleoendemismos), especialmente si hay aislamiento y condiciones ecológicas sui generis.

En general, las floras de plantas vasculares, como la mayoría de los taxones, incrementan su riqueza de especies de los polos hacia latitudes templadas y de ahí al ecuador. El grado de endemismo también podría seguir esta misma tendencia latitudinal. Las montañas y desiertos mexicanos son típicamente ricos en endemismos y en especies. Las primeras, si tienen una distribución "archipelágica" como ocurre en México, generan grupos polipátridos que incrementan la riqueza de una región. En cuanto a los segundos, también se aplica la regla, especialmente por la antigüedad que tienen en la zona de transición mexicana (Halffter, 1976; Morrone, 2005): las distribuciones archipelágicas antiguas tienden hacia el incremento de la diversidad biológica; la dispersión sólo es el agente inicial, la evolución in situ es el factor fundamental.

Croizat (1958) y Nelson y Platnick (1984) sugieren, con justa razón, que la biogeografía no ha madurado como una ciencia en su propio derecho, con el poder de proponer y resolver problemas. En vez de eso ha persistido como una ciencia descriptiva de las relaciones entre el mundo físico y el biológico. Llegó el momento de decir que para México, la biogeografía puede madurar como una ciencia teórica y predictiva de las distribuciones de animales y plantas, evitando lo dicho anteriormente por estos autores, ya que tenemos los elementos y herramientas necesarias para lograrlo. Recientemente y refiriéndose a la biogeografía histórica, Knapp (2005) ha dicho textualmente que the broadness of biogeography is its unique strength, refiriéndose a los múltiples enfoques hoy en voga, mismos que dependen de qué pregunta está interesado en explicar un determinado investigador. Para esta autora, la biogeografía histórica es un conjunto de disciplinas que permite contestar diferentes conjuntos de preguntas, las cuales pueden estar relacionadas con: a) taxones individuales, b) áreas, o c) floras o faunas completas.

Actualmente existen diversos enfoques en biogeografía histórica que intentan resolver diferentes preguntas, mismos que pueden combinarse dentro de un mismo estudio. De esta forma, un trabajo de tipo biogeográfico puede consistir de varias etapas en las cuales se pueden aplicar diferentes métodos, dependiendo de la pregunta a contestar (Luna et al., 2000, 2001). Aunque muchos de estos enfoques han sido considerados como antagónicos o programas de investigación en competencia (v. gr. la panbiogeografía con respecto a la biogeografía de la vicarianza; Crisci y Morrone, 1992; Morrone y Crisci, 1995; Crisci et al., 2000), se ha probado que pueden ser utilizados en diferentes fases de un mismo análisis biogeográfico, contestando diferentes preguntas. La homología biogeográfica de los taxones puede ser obtenida a partir de los trazos generalizados de la panbiogeografía; las relaciones entre las áreas de distribución de los taxones y la secuencia de su fragmentación pueden obtenerse mediante la biogeografía cladística.

Un nuevo dinamismo teórico se abrió con el paradigma de la búsqueda de la interrelación de taxones endémicos y áreas de endemismo (sean plantas, animales y hongos), buscando congruencia con los distintos modelos geológicos propuestos. Algunos de estos modelos conciben México y las áreas adyacentes del Caribe y América Central como un área compuesta o nodo, esto es, un área de convergencia tectónica. Por ende, México es un área biogeográfica que posee una biota compleja, donde no basta con reconocer el elemento endémico, sino que es indispensable establecer sus relaciones filogenéticas, para descubrir las relaciones históricas de cada una de las subáreas y centros de endemismo de las que está compuesta.

Con esta perspectiva, se considera que se han trazado nuevas fronteras en la biogeografía histórica de México, en particular de la biogeografía de las plantas, y ahora se tiene una triple tarea: 1) la actividad descriptiva y sistemática del 
proyecto florístico y taxonómico tradicional; 2) con base en el primero, pero paralelamente, comenzar el estudio de los patrones de interrelación de taxones endémicos de México, considerando a este país más allá del Megaméxico 3 propuesto por Rzedowski (1991b), para comprender otras áreas con las que las relaciones evolutivas puedan ser más antiguas, lejanas y complejas, v. gr. las Antillas, y 3) la conjunción de los 2 puntos anteriores, nos daría la pauta para obtener un atlas biogeográfico de México, en el sentido de Morrone y Espinosa (1998).

El estudio de los patrones de interrelación de taxones endémicos se podría basar en taxones que tengan las siguientes características: 1) distribución geográfica amplia; 2) muy diversificados; 3) alto porcentaje de endemismos a México y Mesoamérica, América del Norte y/o las Antillas, y 4) gran fidelidad ecológica, esto es, que los taxones tengan una distribución típicamente tropical, típicamente de montaña o de ambientes áridos.

La idea básica es que los patrones de taxones endémicos de distribución montana deberían ser congruentes con aquellos de distribución tropical, es decir, se esperaría que hubiesen patrones de distribución complementarios análogos a los esperados por los paleontólogos con el registro fósil costero y terrestre: la homogeneidad observada en un medio implica la disyunción en el otro, lo que, traducido a la biota de México implicaría que el rompimiento de las áreas tropicales estaría asociado posiblemente con el surgimiento de una cordillera que, a su vez, daría lugar a la expansión de las áreas de distribución de la biota montana. Ésta es una de las primeras predicciones de la hipótesis vicariancista aplicada a México.

Ahora bien, ¿qué información nos proporciona el análisis de interrelación entre taxones endémicos?, ¿cuáles son las perspectivas de aplicación de los resultados de un análisis de este tipo? Esta forma de análisis nos permite obtener áreas naturales, es decir, patrones generados por la evolución conjunta de forma y espacio. Sería posible abordar los problemas de la evaluación de áreas protegidas bajo otra perspectiva. En esta forma, a los estimadores usuales de rareza demográfica, de hábitat y geográfica, se añade el de rareza filogenética, implícito en las evaluaciones desarrolladas en los últimos 30 años por la biogeografía cladística. Incorporar nuevos criterios al problema de la conservación permite enriquecer el debate acerca de las prioridades de conservación del medio natural de México y el mundo.

La biogeografía histórica, como una disciplina independiente dentro de la biología comparada, debe tener un programa de investigación independiente, que le permita operar de manera paralela a la sistemática, sin que tenga una restricción de esta última. No podemos negar que la historia de la Tierra y la vida están unidas $\mathrm{y}$ han evolucionado conjuntamente (Croizat, 1958), y como biólogos tendemos a dar una mayor importancia a la historia de la vida (Nihei, 2006), tendencia que no tendría, por ejemplo, un geólogo.

\section{Agradecimientos}

A Juan José Morrone y Raúl Contreras por la lectura crítica del manuscrito.

\section{Literatura citada}

Acosta de, J. 1570. Historia natural y moral de Indias, 2 vols. Sevilla.

Álvarez, T. y F. de Lachica. 1974. Zoogeografía de los vertebrados de México. In El escenario geográfico, D. A. Flores, L. G. Quintero, T. Álvarez y F. de Lachica (eds.). Instituto Nacional de Antropología e Historia, México, D.F. $335 \mathrm{p}$.

Andrés, R., J. J. Morrone, T. Terrazas y L. López-Mata. 2006. Análisis de trazos de las especies mexicanas de Rhus subgénero Lobadium (Angiospermae: Anacardiaceae). Interciencia 31:901-904.

Arriaga, L., D. Espinosa, C. Aguilar y R. Jiménez. (coords.). 1997. Regionalización ecológica y biogeográfica de México. Programa Regiones de Biodiversidad de América del Norte (Informe técnico). Comisión Nacional para el Conocimiento y Uso de la Biodiversidad, Comisión de Cooperación Ambiental y WWF, México, D.F

Avise, J. C. 1998. The history and purview of phylogeography: a personal reflection. Molecular Ecology 7:371-379.

Axelrod, D. I. 1960. The evolution of flowering plants. In The evolution of life. Its origin, history and future (Evolution after Darwin, vol. I.). University of Chicago Press, Illinois. p. 227-305.

Axelrod, D. I. 1979. Age and origin of the Sonoran desert. Occasional Papers, California Academy of Sciences 132:1-74.

Ball, I. R. 1976. Nature and formulation of biogeographical hypotheses. Systematic Zoology 24:407-430.

Becerra, J. X. 2005. Timing the origin and expansion of the Mexican tropical dry forest. Proceedings of the National Academy of Sciences 102:10919-10923.

Braun, E. L. 1955. The phytogeography of unglaciated eastern United States and its interpretation. Botanical Review 21:297-375.

Brooks, D. R. y M. G. P. Van Veller. 2003. Critique of parsimony analysis of endemicity as a method of historical biogeography. Journal of Biogeography 30:819-825.

Brundin, L. 1966. Transantarctic relationships and their significance, as evidenced by chironomid midges. Kongliga Svenska Vetenskaps-Akademiens Handlingar 4:1-472.

Brundin, L. 1981. Croizat's panbiogeography versus phylogenetic biogeography. In Vicariance biogeography: a critique, G. 
Nelson y D. E. Rosen (eds.). Columbia University Press, New York. p. 94-158.

Brundin, L. 1988. Phylogenetic biogeography. In Analytical biogeography: an integrated approach to the study of animals and plant distribution, A. A. Myers y P. S. Giller (eds.).Chapman \& Hall, London, New York. p. 343-369.

Casas-Andreu, G. y T. Reyna-Trujillo. 1990. Provincias herpetofaunísticas. In Herpetofauna (anfibios y reptiles). IV.8.6. Atlas nacional de México, vol. II, escala 1:8000000. Instituto de Geografía, UNAM, México, D.F.

Ceballos, G. y D. Navarro. 1991. Diversity and conservation of Mexican mammals. In Latin American mammalogy: history, biodiversity, and conservation, M. A. Mares y D. J. Schmidly (eds.). University of Oklahoma Press. p. 167-198.

Chávez, J. M. y N. Trigo (coords.) 1996. Programa de manejo para el Parque Nacional Iztaccíhuatl-Popocatépetl. Universidad Autónoma Metropolitana, Unidad Xochimilco, México, D.F. 273 p.

Clausen, R. T. 1959. Sedum of the trans-Mexican volcanic belt: an exposition of taxonomic methods. Comstock, Ithaca, New York.

Colinvaux, P. A., P. E. de Oliveira y M. B. Bush. 2000. Amazonian and Neotropical plant communities on glacial time scales: The failure of the aridity and refuge hypotheses. Quaternary Science Reviews 19:141-169.

Contreras-Medina, R. 2006. Los métodos de análisis biogeográfico y su aplicación a la distribución de las gimnospermas en México. Interciencia 31:76-182.

Contreras-Medina, R. y H. Eliosa-León. 2001. Una visión panbiogeográfica preliminar de México. In Introducción a la biogeografía en Latinoamérica: teorías, conceptos, métodos y aplicaciones, J. Llorente y J. J. Morrone (eds.). Comisión Nacional para el Conocimiento y Uso de la Biodiversidad y Universidad Nacional Autónoma de México, México, D.F. p. $197-212$.

Contreras-Medina, R. e I. Luna. 2002. On the distribution of gymnosperm genera, their areas of endemism and cladistic biogeography. Australian Systematic Botany 15:193-203.

Contreras-Medina, R., I. Luna y J. J. Morrone. 1999. Biogeographic analysis of the genera of Cycadales and Coniferales (Gymnospermae): a panbiogeographic approach. Biogeographica 75:163-176.

Contreras-Medina, R., I. Luna y J. J. Morrone. 2001. Conceptos biogeográficos. Elementos 41:33-37.

Contreras-Medina, R., I. Luna y J. J. Morrone. 2007a. Gymnosperms and cladistic biogeography of the Mexican transition zone. Taxon 56:905-915.

Contreras-Medina, R., I. Luna y J. J. Morrone. 2007b. Application of parsimony analysis of endemicity (PAE) to Mexican gymnosperm distributions: Grid-cells, biogeographic provinces and track analysis. Biological Journal of the Linnean Society 92:405-417.

Corona, M.A., V. M. Toledo y J. J. Morrone. 2007. Does the transMexican volcanic belt represent a natural biogeographical unit. An analysis of the distributional patterns of Coleoptera. Journal of Biogeography 35:1008.1015.

Cracraft J. y R. O. Prum. 1988. Patterns and processes of diversification: speciation and historical congruence in some
Neotropical birds. Evolution 42:603-620.

Craw, R. C. 1988. Continuing the synthesis between panbiogeography, phylogenetic systematics and geology as illustrated by empirical studies on the biogeography of New Zealand and the Chatam Islands. Systematic Zoology 37:291-310.

Craw, R. C., J. R. Grehan y M. J. Heads. 1999. Panbiogeography: Tracking the history of life. Oxford University Press. Oxford. 229 p.

Crisci J. V. 2001. The voice of historical biogeography. Journal of Biogeography 28:157-168.

Crisci J. V. y J. J. Morrone. 1992. Panbiogeografía y biogeografía cladística: paradigmas actuales de la biogeografía histórica. Ciencias, Numero Especial 6:87-97.

Crisci J. V., L. Katinas y P. Posadas. 2000. Introducción a la teoría y práctica de la biogeografía histórica. Sociedad Argentina de Botánica, Buenos Aires. 169 p.

Croizat, L. 1958. Panbiogeography. Publicada por el autor. Caracas. $1731 \mathrm{p}$.

Crum, H. A. 1951. The Appalachian-Ozarkian element in the moss flora of Mexico with a checklist of all known Mexican mosses. Ph. D. Thesis, Universidad de Michigan, Ann. Arbor. $504 \mathrm{p}$.

Cuenca, A., A. E. Escalante y D. Piñero. 2003. Long distance colonization, isolation by distance, and historical demography in a relictual Mexican pinyon pine (Pinus nelsonii Shaw) as revealed by paternally inherited genetic markers (cpSSRs). Molecular Ecology 12:2087-2097.

Darlington, P. J. 1938. The origin of the fauna of the Greater Antilles, with discussion of dispersal of animals over water and through the air. Quarterly Review of Biology 13:274-300.

Darwin, C. 1859. On the origin of species by means of natural selection or the preservation of favoured races on struggle for life. John Murray, London. 477 p.

Dávila-Aranda, P. 1991. Consideraciones filogenéticas y biogeográficas preliminares del género Sorghastrum (Poaceae). Acta Botanica Mexicana 14:59-73.

Dávila-Aranda, P., S. Arias-Montes, R. Lira-Saade, J. L. Villaseñor y A. Valiente-Banuet. 2002. Phytogeography of the columnar cacti (tribe Pachycereeae) in Mexico: a cladistic approach. In Columnar cacti and their mutualists: evolution, ecology and conservation, T. H. Fleming y A. Valiente-Banuet (eds.). University of Arizona Press, Tucson. p. 25-41.

De Candolle, A. P. 1820. Géographie botanique. In Dictionaire des Sciences Naturelles. p. 352-422.

Delgado, P. y D. Piñero. 2002. Sistemática filogeográfica y sus aplicaciones a la evolución y conservación de los bosques de coníferas en México: el caso de Pinus montezumae y $P$. pseudostrobus. Acta Universitaria (Guanajuato) 12:3-19.

Delgadillo, C. 1971. Phytogeographic studies on alpine mosses of Mexico. Bryologist 74:331-346.

Delgadillo, C. 1979. Mosses and phytogeography of the Liquidambar forest of Mexico. Bryologist 82:432-449.

Delgadillo, C. 1986. The Meso-American element in the moss flora of Mexico. Lindbergia 12:121-124.

Delgadillo, C. 1987. Moss distribution and the phytogeographical 
significance of the Neovolcanic belt of Mexico. Journal of Biogeography 14:69-78.

Delgadillo, C., J. L. Villaseñor y P. Dávila. 2003. Endemism in the Mexican flora: a comparative study in three plant groups. Annals of the Missouri Botanical Garden 90:25-34.

De Souza, D. 1991. Refuge model simulations. Testing the theory. Revista Brasileira de Entomologia 35:803-812.

Dirzo, R. 1990. La biodiversidad como crisis ecológica actual, qué sabemos? Ciencias, Número Especial 4:48-55.

Donnelly, T. W. 1988. Geologic constraints on Caribbean biogeography. In Zoogeography of Caribbean insects, J. K. Liebherr (ed.). Cornell University Press, Ithaca. p. 15-37.

Dressler, R. L. 1954. Some floristic relationships between Mexico and the United States. Rhodora 56:81-96.

Ebach, M. y J. J. Morrone. 2005. Forum on historical biogeography: What is cladistic biogeography? Journal of Biogeography 32:2179-2187.

Eldredge, N. 1998. Life in the balance. Humanity and the biodiversity crisis. Princeton University Press, New Jersey. $224 \mathrm{p}$.

Engler, A. 1882. Versuch einer Entwicklungsgeschichte der Pflanzenwelt, insbesondere der Florengebiete seit der Tertiaerperiode. Parte II. Die extratropischen Florengebiete der suedlichen Hemisphaere and die tropischen Gebiete. W. Engelmann, Leipzig. 386 p.

Escalante, P. y J. Llorente. 1985. Riqueza y endemismo de aves y mariposas como criterio para determinar áreas de reserva. Datos del estado de Nayarit, México. Primer Simposio Internacional de Fauna Silvestre. The Wildlife Society of Mexico, México, D.F. 12 p.

Espinosa, D. y J. J. Morrone. 2000. On the integration of track and cladistic methods for selecting and ranking areas for diversity conservation. Journal of Comparative Biology 3:171-175

Espinosa, D., C. Aguilar y T. Escalante. 2001. Endemismo, áreas de endemismo y regionalización biogeográfica. In Introducción a la biogeografía en Latinoamérica: teorías, métodos y aplicaciones, J. Llorente y J. J. Morrone (eds.). Las Prensas de Ciencias, Universidad Nacional Autónoma de México, México, D.F. p. 31-37.

Espinosa, D., J. Llorente y J. J. Morrone. 2006. Historical biogeographical patterns of the species of Bursera (Burseraceae) and their taxonomic implications. Journal of Biogeography 33:1945-1958.

Espinosa-García, F. J., J. L. Villaseñor y H. Vibrans. 2004. Geographical patterns in native and exotic weeds of Mexico. Weed Technology 18:1552-1558.

Fa, J. E. y L. M. Morales. 1991. Mammals and protected areas in the trans-Mexican neovolcanic belt. In Topics in Latin American mammalogy: Ecology, conservation and education, M. A. Mares y D. J. Schmidly (eds.). Oklahoma University, Oklahoma City. p. 196-227.

Fernald, M. L. 1931. Specific segregation and identities in some floras of eastern North America and the Old World. Rhodora $33: 25-63$

Ferrusquía-Villafranca, I. 1990. Provincias bióticas (con énfasis en criterios morfotectónicos). In Regionalización biogeográfica. IV.8.10. Atlas nacional de México, vol. II, escala 1:4000000. Instituto de Geografía, UNAM, México, D.F.

Flores-Villela, O. 1991. Análisis de la distribución de la herpetofauna en México. Tesis, doctorado. Universidad Nacional Autónoma de México. México, D.F. [págs]

Flores-Villela, O. y P. Gerez. 1999. Biodiversidad y conservación en México: vertebrados, vegetación y uso de suelo. Universidad Nacional Autónoma de México y Comisión Nacional para el Conocimiento y Uso de la Biodiversidad. México, D.F. 349 p.

Fournier, E. 1881. Pars II. Gramineae.Typographeo Reipublicae, Paris. $160 \mathrm{p}$.

Gadow, H. 1907-1909. Altitude and distribution of plants in southern Mexico. Journal of the Linnean Society of Botany 38:429-440.

Gentry, A. H. 1982. Neotropical floristic diversity: Phytogeographical connections between Central and South America, Pleistocene climatic fluctuations, or an accident of the Andean orogeny? Annals of the Missouri Botanical Garden 69:557-593.

Goldman, E. A. y R. T. Moore. 1946. The biotic provinces of Mexico. Journal of Mammology 26:347-369.

González, S. y J. Rzedowski. 1984. Algunos aspectos ecológicos y fitogeográficos de las especies de Cyperaceae en el Valle de México. II. Análisis fitogeográfico. Boletín de la Sociedad Botánica de México 46:29-35.

González-Medrano, F. 2003. Las comunidades vegetales de México. Propuesta para la unificación de la clasificación y nomenclatura de la vegetación de México. Instituto Nacional de Ecología, México, D. F. 77 p.

Graham, G. 1972. Some aspects of Tertiary vegetational history about the Caribbean basin. Memorias del Simposio. I Congreso Latinoamericano de Botánica, Sociedad Botánica de México, México, D.F. p. 97-117.

Graham, G. 1973. History of the arborescent temperate element in the northern Latin America biota. In Vegetation and vegetational history of northern Latin America, A. Graham (ed.). Elsevier, Amsterdam. p. 301-314.

Graham, A. 1979. Distribution and migration of Cenozoic floras in Mesoamerica. Boletín del Instituto de Geología de la Universidad Nacional Autónoma de México 101:166-181.

Guzmán, G. 1973. Some distributional relationships between Mexico and United States mycofloras. Mycologia 45:1319-1330.

Haffer, J. 1969. Speciation in Amazonian forest birds. Science 165:131-136.

Halffter, G. 1964a. La entomofauna americana, ideas acerca de su origen y distribución. Folia Entomológica Mexicana 6:1-108.

Halffter, G. 1964b. Las regiones neártica y neotropical desde el punto de vista de su entomofauna. Anais do II Congreso Latino-Americano de Zoología, Sao Paulo 1:51-61.

Halffter, G. 1976. Distribución de los insectos en la zona de transición mexicana. Relaciones con la entomofauna de Norteamérica. Folia Entomológica Mexicana 35:1-64.

Halffter, G. 1978. Un nuevo patrón de dispersión en la zona de transición mexicana: el mesoamericano de montaña. Folia Entomológica Mexicana 39-40: 219-222. 
Halffter, G. 1992. Diversidad biológica y cambio global. Ciencia y Desarrollo 18:33-38.

Halffter, G., J. Soberón, P. Koleff y A. Melic (eds.). 2005. Sobre diversidad biológica: el significado de las diversidades alfa, beta y gamma. $\mathrm{m} 3 \mathrm{~m}$. Monografías Tercer Milenio, vol. 4, Zaragoza. p. 1-242.

Hemsley, W.B. 1886-1888. Botany, volume IV. In Biologia Centrali-Americana, F. D. Godwin y O. Salvin (eds.). R. H. Porter, London. p. 1-498.

Hennig, W. 1950. Grundzüge Einer Theorie der Phylogenetischen Systematik. University of Illinois Press, Urbana. 370 p.

Hennig, W. 1968. Elementos para una sistemática filogenética. Editorial Universitaria de Buenos Aires. 353 p.

Hernández-X., E., H. Crum, W. B. Fox y A. J. Sharp. 1951. A unique vegetational area in Tamaulipas. Bulletin of the Torrey Botanical Club 78:458-463.

Hooker, J.D. 1844-1847. Flora Antartica, 1 vol. and 1 vol. of plates. In Botany of the Antarctic voyage: volume 2. Reeve Brothers, London.

Humboldt, A. I. 1816. Voyage aux régions equinoxiales du nouveau continent, fait en 1799, 1800, 1801, 1802, 1803 et 1804 par A. de Humboldt et A. Bonpland... avec un atlas géographique et physique. A la Libraire Grecque, Paris.

Humboldt, A. I. y A. Bonpland. 1805. Essai sur la géographie des plantes. Chez Levrault, Scoell et Campagnie, Libraries, Paris,

Humphries, C. J. 2000. Form, space and time: which comes first? Journal of Biogeography 27:11-15.

Humphries, C. J. y L. R. Parenti. 1999. Cladistic biogeography, 2a. edición. Oxford University Press, Oxford. 199 p.

Knapp, S. 2005. Biogeography -space, form and time. Journal of Biogeography 32:3-4.

Knapp S. y J. Mallet. 2003. Refuting refugia? Science 300:71-72.

Kohlmann, B. y S. Sánchez. 1984. Estudio areográfico del género Bursera Jacq. ex L. (Burseraceae) en México: una síntesis de métodos. In Métodos cuantitativos en la biogeografía, E. Ezcurra, M. Equihua, B. Kohlmann y S. Sánchez-Colón (eds.). Instituto de Ecología, A.C. Jalapa. p. 41-120.

Laurance, W.F. 2006. Have we overstated the tropical biodiversity crisis? Trends in Ecology and Evolution 22:65-70.

Lavin, M., B. D. Schire, G. Lewis, R. T. Pennington, A. DelgadoSalinas, M. Thulin, C. E. Hughes, A. Beyra-Matos y M. F. Wojciechowski. 2004. Metacommunity process rather than continental tectonic history better explains geographically structured phylogenies in legumes. Philosophical Transactions of the Royal Society of London B 359:1509-1522.

Lavin, M., P. Herendeen y M. F. Wojciechowski. 2005. Evolutionary rates analysis of Leguminosae implicates a rapid diversification of lineages during the Tertiary. Systematic Biology 54:530-549.

Leopold, A. S. 1950. Vegetation zones in Mexico. Ecology 31:507-518.

Levin, P.S. y D.A. Levin. 2002. The real biodiversity crisis. American Scientist 90:6.

Liebherr, J. K. 1991. A general area cladogram for montane Mexico based on distributions in the Platynine genera Elliptoleus and Calathus (Coleoptera: Carabidae). Proceedings of the Entomological Society of Washington 93:390-406.
Linneo, C. 1744. Oratio Telluris habitabilis incremento. Leiden.

Lozano-García, S. 1996. La vegetación del Cuaternario tardío en el centro de México: registros palinológicos e implicaciones paleoclimáticas. Boletín de la Sociedad Botánica de México 58:113-127.

Lozano-García, S. y L. Vázquez-Selem. 2005. A high-elevation a Holocene pollen record of Iztaccíhuatl volcano Central Mexico. The Holocene 15:329-338.

Llorente, J. y D. Espinosa. 1991. Una síntesis de las controversias en la biogeografía histórica contemporánea. Ciencia 42:295-312.

Luna, I., O. Alcántara, D. Espinosa y J. J. Morrone. 1999. Historical relationships of the Mexican cloud forests: A preliminary vicariance model applying parsimony analysis of endemicity to vascular plant taxa. Journal of Biogeography 26:1299-1305.

Luna, I. y R. Contreras-Medina. 2000. Distribution of the genera of Theaceae (Angiospermae: Theales): A panbiogeographic analysis. Biogeographica 76:79-88.

Luna, I., O. Alcántara, D. Espinosa y J. J. Morrone. 2000. Track analysis and conservation priorities in the cloud forests of Hidalgo, Mexico. Diversity and Distributions 6:137-143.

Luna, I., O. Alcántara, D. Espinosa y J. J. Morrone. 2001. Biogeographical affinities among Neotropical cloud forests. Plant Systematics and Evolution 228:229-239.

Luna, I. y O. Alcántara. 2002. Placing the Mexican cloud forests in a global context: a track analysis based on vascular plant genera. Biogeographica 78:1-14.

Lynch, L.D. 1988. Refugia. In Analytical biogeography: an integrated approach to the study of animal and plant distributions, A.A. Myers and P.S. Giller (eds.). Chapman and Hall. London. p. 310-342.

MacArthur, R. H. 1965. Patterns of species diversity. Biology Reviews 40:510-533.

MacArthur, R. H. 1972. Geographical ecology/ patterns in the distribution of species. Harper \& Row, New York. 288 p.

Magallón, S. A. 2004. Dating lineages: Molecular and paleontological approaches to the temporal framework of clades. Internacional Journal of Plant Sciences 165:S7-S21.

Magurran, A. E. 1989. Diversidad ecológica y su medición. Vedrá, Barcelona. 200 p.

Martin, P. S. 1958. A biogeography of reptiles and amphibians in the Gómez Farías region, Tamaulipas, Mexico. Miscellaneous publications Museum of Zoology, University of Michigan 101:1-102.

Martin, P. S. y B. E. Harrell. 1957. The Pleistocene history of temperate biotas in Mexico and Eastern United States. Ecology 38:468-480.

Martínez, M. y J. J. Morrone. 2005. Patrones de endemismo y disyunción de los géneros de Euphorbiaceae sensu lato: un análisis panbiogeográfico. Boletín de la Sociedad Botánica de México 77:212-34.

Mayr, E. y R. J. O'Hara. 1986. The biogeographic evidence supporting the Pleistocene forest refuge hypothesis. Evolution 40:55-67.

McVaugh, R. 1943. The vegetation of the granitic flat-rocks of the southeastern United States. Ecological Monographs 13:119-166. 
Méndez-Larios, I., E. Ortiz y J. L. Villaseñor. 2004. Las Magnoliophyta endémicas de la porción xerofítica de la provincia florística del Valle de Tehuacán-Cuicatlán, México. Anales del Instituto de Biología, Universidad Nacional Autónoma de México, Serie Botánica 75:87-104.

Méndez-Larios, I., J. L. Villaseñor, R. Lira, J. J. Morrone, P. Dávila-Aranda y E. Ortiz. 2005. Toward the identification of a core zone in the Tehuacán-Cuicatlán Biosphere reserve, Mexico, based on parsimony analysis of endemicity of flowering plant species. Interciencia 30:267-274.

Miranda, F. y A. J. Sharp. 1950. Characteristics of the vegetation in certain temperate regions of eastern Mexico. Ecology 31:313-333.

Mittermeier, R. y G. Mittermeier. 1992. La importancia de la diversidad biológica de México. In México ante los retos de la biodiversidad, J. Sarukhán (ed.). Comisión Nacional para el Conocimiento y Uso de la Biodiversidad, México, D.F. p. 63-73.

Montero, J. C. 2006. Filogenia molecular de Cestrum L. sección Habrothamnus (Endl.) Schltdl. (Solanaceae): un proceso de diversificación rápida. Tesis, doctorado Instituto de Biología, UNAM, México, D.F. 111 p.

Morrone, J. J. 2001. Biogeografía de América Latina y el Caribe, volumen 3. Manuales y Tesis SEA, Zaragoza. $148 \mathrm{p}$.

Morrone, J. J. 2002. El espectro del dispersalismo: de los centros de origen a las áreas ancestrales. Revista de la Sociedad Entomológica Argentina 61:1-14.

Morrone, J. J. 2005. Hacia una síntesis biogeográfica de México. Revista Mexicana de Biodiversidad 76:207-252.

Morrone, J. J. y J. V. Crisci. 1995. Historical biogeography: introduction to methods. Annual Review of Ecology and Systematics 26:373-401.

Morrone, J. J. y D. Espinosa. 1998. La relevancia de los atlas biogeográficos para la conservación de la biodiversidad mexicana. Ciencia 49:12-16.

Morrone, J. J., D. Espinosa, C. Aguilar y J. Llorente. 1999. Preliminary classification of the Mexican biogeographic provinces: a parsimony analysis of endemicity based on plant, insect, and bird taxa. Southwestern Naturalist 44:507514.

Morrone, J.J. y J. Márquez. Halffter's Mexican transition zone, beetle generalized tracks, and geographical homology. Journal of Biogeography 28:635-650.

Myers, N. y P. S. Giller (eds.). 1988. Analytical biogeography: an integrated approach to the study of animals and plant distribution. Chapman and Hall, London, New York. 437 p.

Myers, N., R. A. Mittermeier, C. G. Mittermeier, G. A. B. Fonseca y J. Kents. 2000. Biodiversity hotspots for conservation priorities. Nature 403:853-858.

Nelson, G. y N. I. Platnick. 1981. Systematics and biogeography: cladistics and vicariance. Columbia University Press, New York. 567 p.

Nelson, G. y N. I. Platnick. 1984. Biogeography. Carolina Biology Readers No. 119. Biological Supply, Burlington, North Carolina. 16 p.

Nihei, S. S. 2006. Misconceptions about parsimony analysis of endemicity. Journal of Biogeography 33:2099-2106.

Novacek, M. J. (ed.). 2001. The biodiversity crisis: losing what counts. American Museum of Natural History Books, New York. 190 p.

Pielou, E. C. 1975. Ecological diversity. Wiley, New York. 165 p.

Platnick, N. I. 1992. Patterns of diversity. In Systematics, ecology, and the biodiversity crisis, N. Eldredge (ed.). Columbia University Press, New York. p. 15-24.

Prance, G. T. (ed.) 1982. Biological diversification in the tropics. Columbia University Press, New York. 714 p.

Puig, H. 1968. Notas acerca de la flora y la vegetación de la sierra de Tamaulipas (México). Anales de la Escuela Nacional de Ciencias Biológicas de México 17:37-49.

Puig, H. 1974. Phytogéographie et ecologie de la Huasteca (NE du Mexique). Tesis, doctorado. Université Paul Sabatier, Toulouse. $547+92$ p.

Puig, H. 1976. Vegetation de la Huasteca, Mexique. Mission Archeologique et Etnologique Française au Mexique. México, D.F. 531 p.

Puig, H. 1989. Análisis fitogeográfico del bosque mesófilo de Gómez Farías. Biotam 1:34-53.

Ramírez-Pulido, J. y A. Castro-Campillo. 1990. Regiones y provincias mastogeográficas. In Regionalización mastofaunística. IV.8.8. Atlas nacional de México, vol. III. Escala 1:4000 000. Instituto de Geografía, UNAM, México, D.F.

Renner, S. S. 2004. Plant dispersal across the tropical Atlantic by wind and sea currents. International Journal of Plant Sciences 165:S23-S33.

Renner, S. S. 2005. Relaxed molecular clocks for dating historical plant dispersal events. Trends in Plant Sciences 10:550-558.

Rojas-Parra, C. 2005. Automatización del método de la panbiogeografía: Identificación de centros de diversidad. Tesis, maestría. Facultad de Estudios Superiores-Zaragoza, UNAM, México, D.F. 68 p.

Ronquist, F. 1997. Dispersal-vicariance analysis: a new approach to the quantification of historical biogeography. Systematic Biology 46:195-203.

Rosen, D.E. 1975. A vicariance model of Caribbean biogeography. Systematic Zoology 24:431-464.

Rosen, D. E. 1978. Vicariant patterns and historical explanation in biogeography. Systematic Zoology 27:159-188.

Rosen, D. E. 1985. Geologic hierarchies and biogeographic congruence in the Caribbean. Annals of the Missouri Botanical Garden 72:636-659.

Rzedowski, J. 1962. Contribuciones a la fitogeografía florística de México. I. Algunas consideraciones acerca del elemento endémico en la flora mexicana. Boletín de la Sociedad Botánica de México 27:52-65.

Rzedowski, J. 1963. El extremo boreal del bosque tropical siempreverde en Norteamérica continental. Vegetation 11:73-198.

Rzedowski, J. 1965. Relaciones geográficas y posibles orígenes de la flora de México. Boletín de la Sociedad Botánica de México 29:21-177.

Rzedowski, J. 1972a. Contribuciones a la fitogeografía florística de México. II. Afinidades geográficas de la flora fanerogámica de diferentes regiones de la República Mexicana. Anales de la Escuela Nacional de Ciencias Biológicas 19:45-48. 
Rzedowski, J. 1972b. Contribuciones a la fitogeografía florística e histórica de México. III. Algunas tendencias en la distribución geográfica y ecológica de las Compositae mexicanas. Ciencia 27:23-132.

Rzedowski, J. 1973. Geographical relationships of the flora of Mexican dry regions. In Vegetation and vegetational history of Northern Latin America, A. Graham (ed.). Elsevier, Amsterdam. p. 6-72.

Rzedowski, J. 1975. An ecological and phytogeographical analysis of the grasslands of Mexico. Taxon 24:67-80.

Rzedowski, J. 1978. Vegetación de México. Limusa, México, D.F. 432 p.

Rzedowski, J. 1990. Nota sobre el elemento africano en la flora adventicia de México. Acta Botanica Mexicana 12:21-24.

Rzedowski, J. 1991a. Diversidad y orígenes de la flora fanerogámica de México. Acta Botanica Mexicana 14:3-21.

Rzedowski, J. 1991b. El endemismo en la flora fanerogámica: una apreciación analítica preliminar. Acta Botanica Mexicana 15:47-64.

Rzedowski, J. 1992. Diversidad del universo vegetal de México: perspectivas de un conocimiento sólido. In México ante los retos de la biodiversidad, J. Sarukhán y R. Dirzo (comps.). Comisión Nacional para el Conocimiento y Uso de la Biodiversidad, México, D.F. p. 251-257.

Rzedowski, J. 1994. Geographical affinities of the riparian trees of Mexico. Mémoires Societé de Biogéographie, 3a. serie 4:37-44.

Rzedowski, J. 1996. Análisis preliminar de la flora vascular de los bosques mesófilos de montaña de México. Acta Botanica Mexicana 35:25-44.

Rzedowski, J. 2005. México como área de origen y diversificación de linajes vegetales. In Regionalización biogeográfica en Iberoamérica y tópicos afines, J. Llorente y J. J. Morrone (eds.). Las Prensas de Ciencias, Universidad Nacional Autónoma de México. México, D.F. p. 375-382.

Rzedowski, J. y T. Reyna-Trujillo. 1990. Divisiones florísticas. In Tópicos fitogeográficos (provincias, matorral xerófilo y cactáceas). IV.8.3. Atlas nacional de México, vol. II, escala 1:8 000 000. Instituto de Geografía,UNAM, México, D.F.

Savage, J. M. 1982. The enigma of the Central American herpetofauna: dispersal or vicariance? Annals of the Missouri Botanical Garden 69:464-547.

Schouw, J. F. 1823. Grundzüge einer allgemeinen Pflanzengeographie. Reimer, Berlin. 524 p.

Sharp, A. J. 1945. Notas sobre la flora de la región escarpada de la parte noroeste del estado de Puebla. Boletín de Biología, Universidad de Puebla 11-12:29-32.

Sharp, A. J. 1946a. Informe preliminar sobre algunos estudios fitogeográficos efectuados en México y Guatemala. Revista de la Sociedad Mexicana de Historia Natural 7:35-44.

Sharp, A. J. 1946b. A preliminary report on some phytogeographical studies in Mexico and Guatemala. American Journal of Botany 33:844.

Sharp A. J. 1953a. Generic correlations in the flora of Mexico and eastern Asia. Journal of the Tennessee Academy of Sciences 28:188.

Sharp, A. J. 1953b. Notes on the flora of Mexico: World distribution of the woody dicotyledonous families and the origin of the modern vegetation. Journal of Ecology 41:374380 .

Sharp, A. J. 1961. The Asiatic element in the flora of Mexico. Association of Southeastern Biologists Bulletin 8:23.

Sharp, A. J., E. Hernández-X., H. Crum y W. B. Fox. 1950. Nota florística de una asociación importante del suroeste de Tamaulipas, México. Boletín de la Sociedad Botánica de México 11:1-4.

Smith, H. 1941. Las provincias bióticas de México, según la distribución geográfica de las lagartijas del género Sceloporus. Anales de la Escuela Nacional de Ciencias Biológicas 2:103-110.

Soulé, M. 1992. Conservation biology today: The most pressing questions. In México ante los retos de la biodiversidad, J. Sarukhán y R. Dirzo (comps.). Comisión Nacional para el Conocimiento y Uso de la Biodiversidad, México, D.F. p. 57-62.

Standley, P. C. 1936. Las relaciones geográficas de la flora mexicana. Anales del Instituto de Biología, Universidad Nacional Autónoma de México 7:9-16.

Steyermark, J. A. 1950. Flora de Guatemala. Ecology 31:368372.

Stuart, L. C. 1964. Fauna of Middle America. In Handbook of Middle America Indians, vol. 1, R. C. West (ed.). p. 316-363.

Stromeyer, F. 1800. Commentatio inauguralis sistens historiae vegetabilium geographicae specimen. Göttingen.

Toledo, V. 1976. Los cambios climáticos del Pleistoceno y sus efectos sobre la vegetación tropical cálida y húmeda de México. Tesis, maestría. Facultad de Ciencias, Universidad Nacional Autónoma de México, México, D.F. 73 p.

Toledo, V. 1982. Pleistocene changes of vegetation in tropical Mexico. In Biological diversification in the tropics, G. T. Prance (ed.). Proceedings of the fifth Internacional Symposium of the Association for Tropical Biology. Columbia University Press, New York. p. 93-111.

Toledo, V. 1988. La diversidad biológica de México. Ciencia y Desarrollo 81:17 -29.

Toledo V. M y M. J. Ordoñez. 1993. The biodiversity scenario of México: a review of terrestrial habitats. In Biological diversity of México: origins and distribution, T.P. Ramamoorthy R. Bye, A. Lot y J. Fa (eds.). Oxford University Press, New York. p. 757-777.

Toledo, V. M., A. M. Corona y J. J. Morrone. 2007. Track analysis of the Mexican species of Cerambycidae (Insecta, Coleoptera). Revista Brasileira de Entomologia 51:131-137.

Torres-Miranda, A. e I. Luna. 2006. Análisis de trazos para establecer áreas de conservación en la faja volcánica transmexicana. Interciencia 31:849-855.

Trelease, W. 1924. The American oaks. Memoires of the National Academy of Sciences 20:1-255.

Uetz, P. 2000. How many reptiles species? Herpetological Review 31:13-15.

van der Hammen, T. y J. Hooghiemstra. 2000. Neogene and Quaternary history of vegetation, climate, and plant diversity in Amazonia. Quaternary Science Reviews 19:725-742.

Vane-Wright R. J., C. J. Humphries y P. H. Williams. 1991. What to protect? Systematics and the agony of choice. Biological Conservation 55:235-254. 
Villaseñor, J. L. 2003. Diversidad y distribución de las Magnoliophyta de México. Interciencia 28:160-167.

Villaseñor, J. L. 2004. Los géneros de plantas vasculares de la flora de México. Boletín de la Sociedad Botánica de México 75:105-135.

Villaseñor, J. L. y F. Espinosa-García. 2004. The allien flowering plants of Mexico. Diversity and Distributions 10:113-123.

Villaseñor, J. L., G. Ibarra-Manríquez, J. A. Meave y E. Ortiz. 2005a. Higher taxa as surrogates of plant biodiversity in a megadiverse country. Conservation Biology 19:232-238.

Villaseñor, J. L., P. Maeda, J. J. Colín-López y E. Ortiz. 2005b. Estimación de la riqueza de especies de Asteraceae mediante extrapolación a partir de datos de presencia-ausencia. Boletín de la Sociedad Botánica de México 76:5-18.

Villaseñor, J. L., C. Delgadillo y E. Ortiz. 2006. Biodiversity hotspots from a multigroup perspective: mosses and senecios in the transmexican volcanic belt. Biodiversity and
Conservation 15:4045-4058.

Wallace, A. R. 1876. The geographical distribution of animals, with a study of the relations of living and extinct faunas as elucidating the past changes of the Earth's surface. Macmillan, London. 1110 p.

Watson, S. 1890. The relation of the Mexican flora to that of the United States. Proceedings of the American Association for the Advancement of Science 39:291-292.

Wegener, A. 1929. The origin of continents and oceans. Dover, New York. 246 p.

Willis, K.J. y R. J. Whittaker. 2000. The refugial debate. Science 287:1406-1407.

Wilson, E. O. 1989. La biodiversidad amenazada. Investigación y Ciencia 158:64-71.

Wulff, E. V. 1950. History of the science. In An introduction to historical plant geography. Chronica Botanica, Waltham, Massachusetts. p. 1-24. 